\title{
SHOCK TEMPERATURES IN SILICA GLASS: IMPLICATIONS FOR MODES OF SHOCK-INDUCED DEFORMATION, PHASE TRANSFORMATION, AND MELTING WITH PRESSURE
}

\author{
Douglas R. Schmitt ${ }^{1}$ and Thomas J. Ahrens \\ Seismological Laboratory, California Institute of Technology,Pasadena
}

\begin{abstract}
Gray body temperatures and emittances of silica glass under shock compression between 10 and $30 \mathrm{GPa}$ are determined. Observed radiative temperatures are higher than computed continuum temperatures for shockcompressed silica glass; however, below $\sim 26 \mathrm{GPa}$ observed emittances are $<0.02$. This suggests that fused quartz deforms heterogeneously in this shock pressure range as has been observed in other minerals. Between 10 and $16 \mathrm{GPa}$, radiative temperatures decrease from $4400 \mathrm{~K}$ to $3200 \mathrm{~K}$, whereas above $16-30 \mathrm{GPa}$, gray body temperatures of $\sim 3000 \mathrm{~K}$ with low emittances are observed. The emittances increase with pressure from 0.02 to 0.9 . The pressure range from 10 to $16 \mathrm{GPa}$ coincides with the permanent densification region, while the $16-30 \mathrm{GPa}$ range coincides with the inferred mixed phase region along the silica glass Hugoniot. The differing radiative behaviors may relate to these modes of deformation. Based upon earlier shock recovery experiments and a proposed model of heterogeneous deformation under shock compression, the temperatures associated with low emittances in the mixed phase region probably represent the melting temperature of the high-pressure phase, stishovite, which can be expected to crystallize from a melt in hot zones. Above $20 \mathrm{GPa}$ the melting temperature of stishovite would therefore be $3000 \mathrm{~K} \pm 200 \mathrm{~K}$ and almost independent of pressure to $30 \mathrm{GPa}$. The effects of pressure on melting relations for the system $\mathrm{SiO}_{2}-\mathrm{Mg}_{2} \mathrm{SiO}_{4}$ are considered together with the proposed stishovite melting curve and suggested maximum solidus temperatures within the mantle of $\sim 2370 \mathrm{~K}$ at $12.5 \mathrm{GPa}$ and $\sim 2530 \mathrm{~K}$ at $20.0 \mathrm{GPa}$. Using the proposed stishovite melting temperatures $\mathrm{T}_{\mathrm{m}}$ and estimates of upper mantle temperatures $\mathrm{T}$, the effective viscosity, which can be considered a function of the homologous temperature $\mathrm{T} / \mathrm{T}_{\mathrm{m}}$, appears to remain nearly constant from 200 to $600 \mathrm{~km}$ depth in the Earth.
\end{abstract}

\section{Introduction}

The temperatures of silica glass subject to shock pressures between 10 and $30 \mathrm{GPa}$ were investigated by observation of shock-induced radiative thermal emissions. In this pressure range many brittle materials deform heterogeneously under shock compression with the formation of localized zones of intense deformation and high temperatures surrounded by relatively undamaged cooler material. The study of these zones which are referred to as hot spots, shear bands, or microfaults is important because they play a role in the shock deformation process in

\footnotetext{
${ }^{1}$ Now at Institute for Earth and Planetary Physics and Department of Physics, University of Alberta, Edmonton, Canada.

Copyright 1989 by the American Geophysical Union.

Paper number 88JB04323.

0148-0227/89/88JB-04323\$05.00
}

minerals and particularly in shock production of glassy and high-pressure polymorphs. Spectra of light emitted from silica glass in this pressure range reveal the temperature, and to some extent the spatial density, of these microfaults. Observed temperatures appear to be related to the deformation occurring and, based on models of heterogeneous deformation, constrain the melting curve of minerals with pressure.

Quartz was chosen as a candidate for study for two major reasons. The first is the importance of quartz as both a crustal and a mantle mineral. High-pressure phases of quartz have been discovered at sites of large meteorite impacts and are presumably produced by the action of shock waves. Knowledge of the shock effects in quartz provides information for deducing the effects of large impacts on the Earth. Free $\mathrm{SiO}_{2}$ in the form of coesite or stishovite most likely does not exist in substantial quantities in the mantle despite cosmochemical estimates that it composes $\sim 35 \%$ by weight of the entire Earth but is a constituent of the highpressure phases of pyroxene, olivine, and garnet. Since the lower mantle is often described in terms of high-pressure phase oxide mixtures [Al'tshuler et al., 1965], a better understanding of the high pressure properties of $\mathrm{SiO}_{2}$ yields information pertinent to the study of mantle constitution and dynamics.

Second, $\mathrm{SiO}_{2}$ has been extensively studied in both high-pressure static and dynamic experiments. The highpressure polymorphs coesite [Coes, 1953] and stishovite [Stishov and Popova, 1961] have room pressure densities of 2.92 and $4.29 \mathrm{Mg} / \mathrm{m}^{3}$ [Kuskov and Fabrichnaya, 1987], respectively. Except for the discovery of coesite in kimberlites and deep-seated metamorphic rocks, the only natural occurrences of these minerals are at the sites of major impacts on the Earth's surface, suggesting formation from quartz by shock wave. Evidence (reviewed by Stöffler [1972, 1974]) demonstrates that shock damage in quartz is nonuniformly distributed; shock compression in quartz below $35 \mathrm{GPa}$ is a heterogeneous process. Observation of the radiative temperatures of fused $\mathrm{SiO}_{2}$ under shock compression will aid in further understanding of shock processes in brittle minerals.

Previous high-pressure work on $\mathrm{SiO}_{2}$ is reviewed and a model of the shock deformation process in silica glass is presented. Results of shock temperature measurements from fused quartz in the pressure range from 10 to $35 \mathrm{GPa}$ are interpreted in light of this model, and implications for the mantle are suggested.

\section{Background}

We consider the microscopic effects of the passage of a shock wave through a solid brittle medium with emphasis on silica glass. Covalently bonded minerals of geophysical interest undergo brittle deformation according to Grady [1980]. Shock deformation of partially covalent minerals, such as $\mathrm{SiO}_{2}, \mathrm{MgO}, \mathrm{Al}_{2} \mathrm{O}_{3}$, and $\mathrm{CaCO}_{3}$, is characterized by all or some of the following features: (1) the existence of large Hugoniot elastic 
limits, (2) a fluid like release from high pressure, (3) a nonequilibrium Hugoniot in the mixed phase region for minerals with a primary coordination phase change, and (4) the observation of heterogeneities in minerals recovered from a shock wave experiment.

The Hugoniot elastic limit (HEL) is the shock pressure at which dynamic yielding occurs; shock compression below the HEL is an elastic process, and plastic deformation occurs above the HEL [Davison and Graham, 1979]. This results in a first shock propagating slightly faster than the longitudinal sound speed (elastic precursor) with magnitude equal to the HEL followed by a slower second shock described as a plastic wave with amplitude of the final shock pressure. Two wave shock structures have been reported in shock compression experiments on both alpha and fused quartz to $75 \mathrm{GPa}$ [Wackerle, 1962; Fowles, 1967; Sugiura et al., 1981]. They attribute the two-wave structure, observed over a wide pressure range, to anomalously high HEL in quartz which has been measured by a variety of methods to range from 5.5 to $15 \mathrm{GPa}$ for differing crystal orientations [Fowles, 1967; Graham, 1974]. Similarly, estimates of the fused quartz HEL range from 8.8 to $9.8 \mathrm{GPa}$ [Wackerle, 1962; Barker and Hollenbach, 1970; Sugiura et al., 1981].

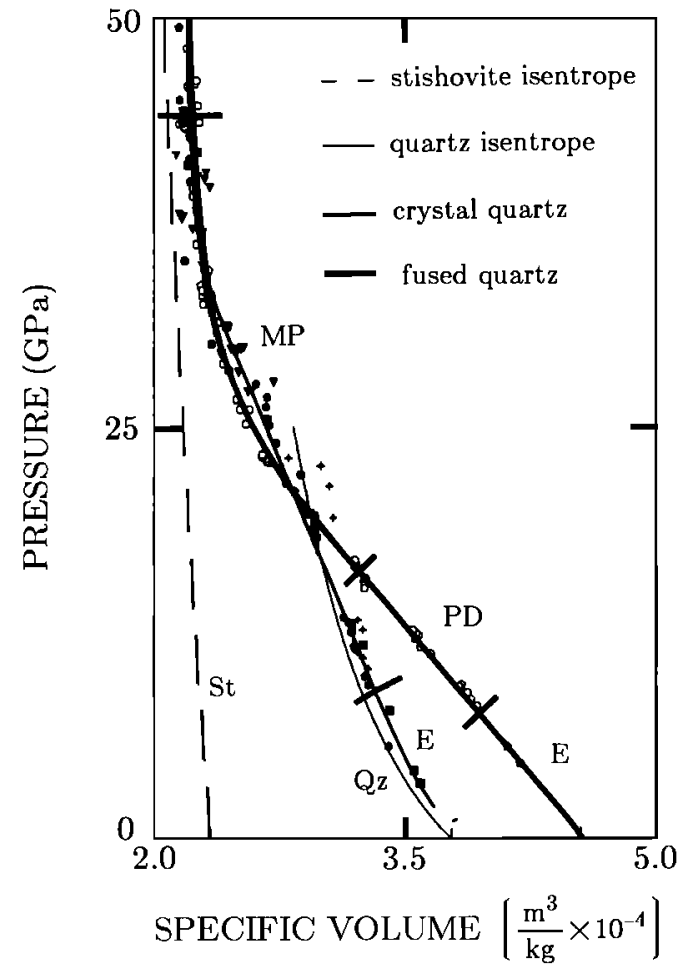

Fig. 1a. Shock pressure versus volume data for crystalline (solid symbols) and fused (open symbols) quartz. Static compression curves for alpha quartz $(\mathrm{Qz})$ (initial density = $2.65 \mathrm{~g} / \mathrm{cm}^{3}$, bulk modulus $=37.1 \mathrm{GPa}$, bulk modulus pressure derivative $=6.0$ ) and stishovite $(\mathrm{St})$ (initial density $=4.288 \mathrm{~g} / \mathrm{cm}^{3}$, bulk modulus $=305 \mathrm{GPa}$, bulk modulus pressure derivative $=4.5$ ) [Kuskov and Fabrichnaya, 1987] calculated with Birch-Murnaghan finite strain theory are shown for comparison. The fused quartz and crystalline quartz Hugoniots coincide above $30 \mathrm{GPa}$, suggesting that they are in the same phase state. Key to regions along Hugoniot: E, elastic deformation below HEL; PD, permanent densification of fused quartz; MP, mixed phase; St, stishovite; T, stishovite to melt transition under homogeneous shock melting; HM, homogeneous shock melting.

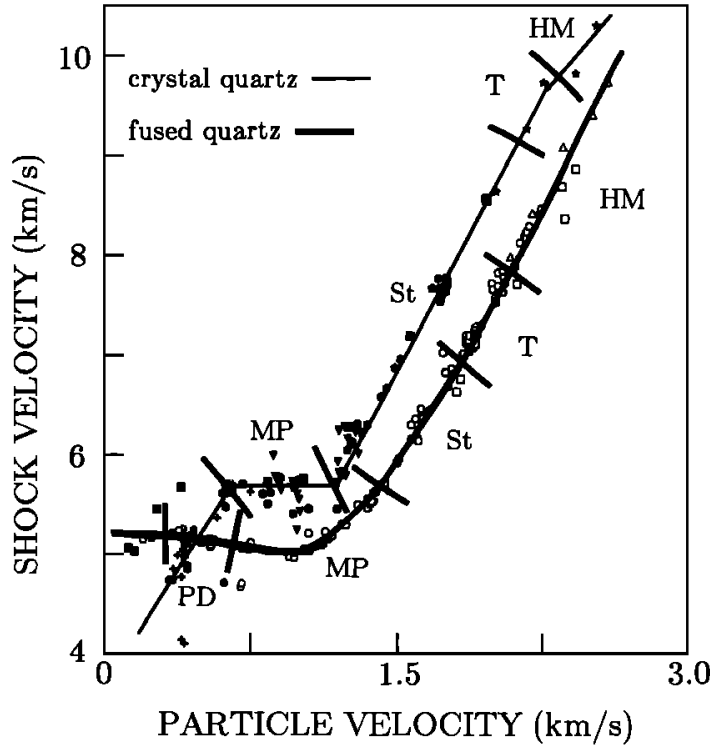

Fig. 1b. Shock wave velocity versus particle velocity for crystalline and fused quartz. Symbols have same meaning as in Figure 1a. Fused quartz data from Lyzenga et al. [1983] (open triangles), Jackson and Ahrens [1979] (open squares), Wackerle [1962] (open pentagons), and Marsh [1980] (open circles). Crystal quartz data from Lyzenga et al. [1983] (solid five-point star), Ahrens and Rosenberg [1968] (solid inverted triangles), Grady et al. [1974] (solid circles), Fowles [1967] (solid four-point stars), Marsh [1980] (solid pentagons), Trunin et al. [1971] (solid squares), and Wackerle [1962] (solid hexagons).

In contrast to metals which retain a finite shear strength above the HEL, evidence was presented in the above studies, indicating that silica loses its rigidity above the elastic limit; that is, the Hugoniot of quartz collapses to predicted static compression curves. Silica compressed above the elastic limit may be characterized as fluid like [Graham, 1974]. This fluid like behavior is best observed during the release of a shock compressed quartz crystal from high pressure. Grady et al. [1975] measured sound velocities from rarefaction wave profiles on the Hugoniot

The Hugoniot of $\alpha$-quartz (Figure 1, solid symbols) supplies evidence for a phase transition, believed to be that of $\alpha$-quartz to stishovite. In the shock wave velocity-particle wave velocity plot of Figure $1 \mathrm{~b}$, shock velocities remain constant over a range in $U_{p}$ of $1.4-2.25 \mathrm{~km} / \mathrm{s}$. Although Wackerle [1962] and Fowles [1967] reported data for both the elastic precursor and the plastic shock, Figure 1 shows results for only the second or plastic wave. Trunin et al. [1971] supply information on one arrival only which may lead to the discrepancy between the data sets at $U_{p}<1.4 \mathrm{~km} / \mathrm{s}$. All data sets display a region of constant shock velocity characteristic of a phase change in $\alpha$-quartz as labelled in Figure 1. This range of particle velocity is equivalent to the pressure range of 14.4 $\mathrm{GPa}$ to approximately $38 \mathrm{GPa}$ and is hereafter referred to as the mixed phase region of the Hugoniot of $\alpha$-quartz. Within this range the incompressibility of quartz increases dramatically, as is seen in Figure 1a of shock pressure versus specific volume.

Wackerle [1962] first suggested that the produced high-pressure phase was stishovite, or a like-coordinated liquid. Based on the comparable large density increase found in both the static and shock wave experiments and 
on the fact that the shock wave and static pressures of phase initiation were similar (approximately $14 \mathrm{GPa}$ ), McQueen et al. [1963] suggested that shock production of stishovite occurred. They further suggested that the short time scale of the shock experiments prohibited large stishovite crystal growth and that instead a fluid with a short-range order stishovite like structure may be created.

Between the HEL ( 8.8-9.8 GPa) and approximately $16.0 \mathrm{GPa}$, fused silica undergoes a permanent densification as evidenced by shock recovery [Wackerle, 1962; Arndt et al., 1971] and particle velocity time profiles [Sugiura et al., 1981]. Gibbons and Ahrens [1971], however, find increased refractive index, indicative of permanent densification, in recovered fused quartz shocked to pressures as high as $30 \mathrm{GPa}$. This permanent densification has been more fully studied in static compression experiments on fused quartz [Bridgman and Simon, 1953] and is attributed to a rearrangement and tilting of the $\mathrm{SiO}_{2}$ tetrahedra [Cohen and Roy, 1961; MacKenzie, 1963; Arndt and Stöffler, 1969; Grimsditch, 1984; Hemley et al., 1986]. This densification is observed to reverse upon annealing of both shock and statically compressed fused quartz to pressures in excess of $10 \mathrm{GPa}$.

Above $16 \mathrm{GPa}$ the Hugoniot of fused quartz passes through a region in which the material may be in a mixed phase with stishovite. The inherent properties of shocked fused quartz have not yet been determined. Note that at approximately $30 \mathrm{GPa}$ and above the Hugoniots of both crystalline and fused quartz converge, suggesting that both are at the same phase state at higher shock pressures. This suggests the fused quartz mixed phase region may contain some stishovite. Sugiura et al. [1981] suggest that compression above $16 \mathrm{GPa}$ is that of a highdensity silica glass; they find little evidence for production of stishovite below $22 \mathrm{GPa}$. However, in recent reshock and release experiments on fused quartz [Chhabildas and Grady, 1984a] at 13 and $21 \mathrm{GPa}$, the stishovite transformation was found to initiate at $13 \mathrm{GPa}$ and to progress to a more fully mixed phase state at $20 \mathrm{GPa}$.

After shock compression a rarefaction or release wave provides a thermodynamic path upon isentropic decompression. The release wave path in the pressurevolume plane yields estimates of the zero pressure density of the high-pressure phase. Experiments on crystalline quartz [Ahrens and Rosenberg, 1968; Grady et al., 1974; Chhabildas and Grady, 1984b; Chhabildas and Miller, 1985; Podurets et al., 1976] indicate that: (1) The transformation to the high pressure phase occurs within the shock front, little further transformation occurs during the remainder of the compression, (2) the release path for quartz shocked to less than 10 to $15 \mathrm{GPa}$ returns to the initial density, (3) the release path of quartz shocked into the mixed-phase region (15 to $34 \mathrm{GPa}$ ) follows a path indicative of mixed quartz-stishovite, the ratio of stishovite increasing proportionally with pressure, and upon release to less than $8 \mathrm{GPa}$, reversion to a lower density approximately that of crystalline quartz, and (4) above 50 $\mathrm{GPa}$ the release path is essentially that of the highpressure phase until a released pressure of $5-8 \mathrm{GPa}$ is reached, whereupon a reversion to a lower-pressure phase with a density of $\sim 2.2 \mathrm{Mg} / \mathrm{m}^{3}$ occurs.

The most direct evidence for the transformation to the high pressure polymorphs is the recovered phases from both natural impact craters and laboratory shock experiments. Abundant coesite and smaller amounts of stishovite have been detected in rocks subjected to high shock pressures during meteorite impacts [Chao et al. 1960, 1962; Kieffer, 1971]. Shock laboratory production of stishovite from quartz in single crystals, novaculite, and sandstone was reported by DeCarli and Milton [1965]. The lack of coesite in their recovered samples is not understood. Kleeman and Ahrens [1973] pointed out that the direct transformation from quartz to stishovite should occur at a pressure of $\sim 7.5 \mathrm{GPa}$ and not $14 \mathrm{GPa}$ and identified stishovite from quartz shocked above 9.0 $\mathrm{GPa}$; increasing quantity was found with increasing pressure until at pressures above $23.4 \mathrm{GPa}$ the production of stishovite decreased with more glass produced. A single shot with fused quartz at $16.6 \mathrm{GPa}$ yielded the largest percentage of stishovite. Most recently, Ashworth and Schneider [1985] report bands of polycrystalline stishovite, producing rings in electron diffraction, associated with densified glass in shock recovered quartz.

Mashimo et al. [1980] suggest that stishovite is not readily observed in shock-recovered material due to its rapid annealing to fused quartz at the elevated residual temperatures upon shock release. Above $600 \mathrm{~K}$, stishovite readily transforms to fused quartz at standard pressure [Dachille et al., 1963].

\section{Model of Heterogeneous Deformation in Ouartz}

Anan'in et al. [1974a] examined recovered crystalline quartz and found the material in a plane perpendicular to the direction of shock propagation was broken up into $5-20 \mu \mathrm{m}$ blocks separated by layers of quartz glass. The plane parallel to the shock front revealed larger $(100-200 \mu \mathrm{m})$ blocks. Anan'in et al. [1974a] suggested that compression above the HEL occurs by fragmentation into blocks which then move relative to one another. A consequence of this movement is frictional heating and melting at the surfaces of the blocks. They further speculated that increases in atomic coordination can occur rapidly within the melt and therefore the melted component, which increases with increasing pressure, accounts for the mixed phase region of the quartz Hugoniot.

Anan'in et al. [1974b] in shock recovery experiments on fused quartz found that it undergoes deformation similar to that of crystalline quartz. As in crystalline quartz, they note that at shock pressures above the HEL, the fused quartz splits into blocks separated by layers of melt. The solid blocks are thus subjected to hydrostatic compression and are permanently densified, whereas the melt takes on the characteristics of a highpressure phase. Moreover, Wackerle [1962] found that fused quartz shocked to $25 \mathrm{GPa}$ transformed to fine particles with densities in the $2.4-2.5 \mathrm{Mg} / \mathrm{m}^{3}$ range whereas material shocked to higher pressures had the normal 2.2 $\mathrm{Mg} / \mathrm{m}^{3}$ density in agreement with index of refraction data [Gibbons and Ahrens, 1971; Arndt et al. 1971].

Gratz [1984], consistent with an earlier study [Schaal and Horz, 1977], observed planar microfaults of thickness of $\sim 1-10 \mu \mathrm{m}$ oriented at $45^{\circ}-55^{\circ}$ to the shock wave propagation direction in approximate agreement with the orientation of the maximum resolved shear stress with respect to the shock propagation direction [Jones and Graham, 1971]. These microfaults are filled with glass; displacement across these microfaults is seen by offset of broken rutile needles separated by a microfault. The observations of steps emerging from the surface perpendicular to the shock direction in scanning electron micrographs [Ashworth and Schneider, 1985] are consistent with the production of microfaults characterized by relative displacements.

The microfaults are to be distinguished from shock lamellae [Stöffler, 1972, 1974], the latter occur in sets of 4 to 12 and are narrow planes of lengths to $50 \mu \mathrm{m}$ and thicknesses of 0.5 to $500 \mathrm{~nm}$ [Gratz, 1984]. Additionally, the shock lamellae have an orientation nearly perpendicular to the shock propagation direction and appear to be crystallographically controlled. Lamellae are apparently formed at the same time as the microfaults. 
Alternatively, a series of tensile cracks, also filled with glass and oriented perpendicular to the shock propagation direction is observed in shock recovered material. These are features of the release of the material from high pressure. These tensile remnants of the shock recovery experiment are smaller than the microfaults, and the glass that they contain appears to have originated in the microfaults and then migrated into the connected tensile cracks upon release (A. Gratz, personal communication, 1987).

Wackerle [1962] found that fused quartz shocked to near $50 \mathrm{GPa}$ were recovered in single pieces. Furthermore, samples composed of several initially divided pieces of fused quartz were recovered as a continuous mass.

Ashworth and Schneider [1985] shock loaded quartz along the a axis to pressures of $30 \mathrm{GPa}$, and although they make no mention of microfaults [Anan'in et al., 1974a; Gratz, 1984], they note regions of patchy glass which could be microfaults when the differences in magnification of the studies are considered. Numerous glass filled lamellae of thicknesses less than $1 \mu \mathrm{m}$ at a crystallographically controlled orientation, as seen by Gratz [1984], parallel to the shock direction were noted. The amorphous material within the lamellae is similar to that produced by the irradiation of quartz (metamictization).

The above observations are evidence for the proposed model of heterogeneous deformation as shown in Figure $2 \mathrm{a}$ after Grady [1980]. In Figure 2a, a shock wave is shown propagating toward the right in a brittle material. The shockcompressed region on the left has experienced a heterogeneous compression and is composed of blocks of solid material separated by layers of melt. The melt layers are oriented at $45^{\circ}$ to the direction of shock propagation (i.e., the direction of maximum shear stress). The solid blocks are subjected to volumetric compression due to application of a hydrostatic stress via the regions of melt.

a)

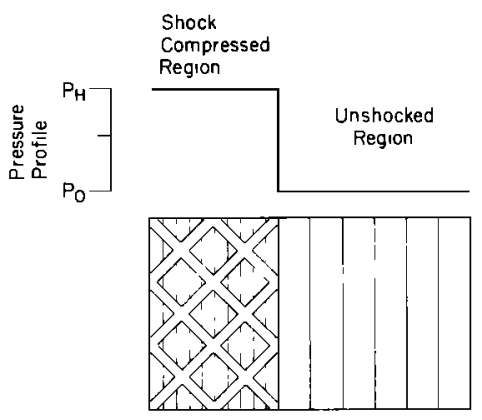

b)

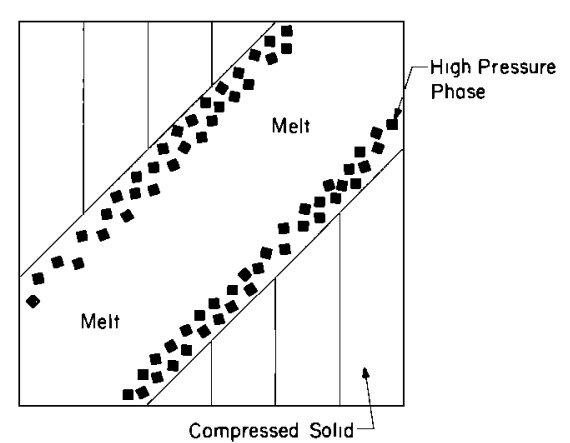

Fig. 2. Schematic of model of heterogeneous shock compression in brittle materials, after Grady et al. [1975]. (a) Large-scale view with shock wave magnitude $P_{h}$ propagating toward the right in a sample. Behind the shock wave, material is compressed and heterogeneous yielding has occurred on planes at $45^{\circ}$ to the direction of shock propagation. (b) Microfault containing melt is surrounded by undamaged material. Upon cooling, high-pressure phase may nucleate.
Figure $2 b$ displays an enlarged view of a microfault. Most of the material within the confines of the microfault is melt of pressure dependent coordination. As cooling of the microfault occurs, high-pressure phase begins to nucleate (solid squares) within the region of melt (light gray region) similar to the observations of Ashworth and Schneider [1985]. In quartz, a change in coordination from 4 to 6 could be easily and rapidly be accomplished in a melt as suggested by the models of Stolper and Ahrens [1987]. Further, this nucleation of high-pressure solid phase in equilibrium with the melt may constrain the temperature of the microfault to that of the fusion curve. The observed temperatures from mixed phase regions along the Hugoniot would be the melting or liquidus temperature of the equilibrium solid phase.

At a high enough shock pressure the volumetric density of these melted or sheared zones becomes large relative to the volume of the undamaged blocks such that rapid equilibration of the shocked material takes place on a time scale much less than the shock wave experiment. At this point the deformation would appear much more homogeneous [Grady, 1977, 1980].

This model explains the loss of shear strength behind the shock front and the phase transformation by shock wave in quartz.

\section{Experimental Procedures}

Experiments were conducted on the $40-\mathrm{mm}$ powder gun at the Seismological Laboratory of the California Institute of Technology in a configuration similar to that of Kondo and Ahrens [1983a]. Planar shock waves were generated within the samples by impact of metal flyer plates (Table 1 and Figure 3) with velocities of up to $2.5 \mathrm{~km} / \mathrm{s}$. Heating of the sample by shock compression resulted in the emission of visible light. This light propagates through the unshocked portion of the sample and is directed to a diffraction grating spectrometer whose output is recorded by a charge coupled device (EG\&G Princeton Applied Research optical multichannel analyzer, model 1257) to give a visible spectrum. This digitally recorded spectrum is then used to determine a gray body temperature for the material while it is under shock compression. In addition to the spectrometer, a photodiode supplies a record of intensity versus time and a framing camera [Schmitt et al., 1986] gives short exposure images of the sample under shock compression.

Cylindrical fused silica samples (T12 Optosil 1, Amersil Corp.) of $2.54 \mathrm{~cm}$ diameter and $0.6 \mathrm{~cm}$ thickness were purchased prepolished to an optical grade flatness. The specific gravity of the samples was measured to an accuracy of $0.02 \%$ by the Archimedean method. Silver was vacuum-deposited on one face to mask light flashes on arrival of the shock wave at the driver-sample interface due to gaps [Kondo and Ahrens, 1983b]. The silver-coated sample face was mounted with epoxy or phenyl salicylate to a metal driver plate (Table 1) which had been polished to a mirror finish with a final corundum grit of $0.3 \mu \mathrm{m}$. An opaque mask with an hole of inside diameter of $13.0 \mathrm{~mm}$ was centered on the sample free surface to eliminate light emissions from regions near the edges of the sample.

Shock pressures were determined with the impedance match method [Duvall and Fowles, 1963] and using the Hugoniot data for fused quartz, magnesium, aluminum, copper, and tungsten by Marsh [1980] and the experimentally determined projectile velocities.

Light recorded by the optical multichannel analyzer passes through a series of photocathode intensifiers which are controlled by a high voltage pulse; the detector may thus be gated to record spectra on time scales as short as 
TABLE 1. Experimental Parameters

\begin{tabular}{|c|c|c|c|c|c|c|c|c|}
\hline Shot & Flyer ${ }^{a}$ & Driver & $\begin{array}{c}\text { Flyer } \\
\text { Velocity } \\
\text { km/s }\end{array}$ & $\begin{array}{l}\text { Pressure } \\
\text { GPa }\end{array}$ & $\begin{array}{c}\text { Temperature } \\
\mathbf{K}\end{array}$ & $\begin{array}{c}\text { Emittance } \\
\times 10^{-3}\end{array}$ & IFE & Field \\
\hline $\begin{array}{l}634 \\
635 \\
684 \\
685 \\
686 \\
687 \\
688 \\
689 \\
691 \\
695 \\
708 \\
709 \\
710 \\
711\end{array}$ & $\begin{array}{l}\mathrm{Al} \\
\mathbf{W} \\
\mathbf{W} \\
\mathbf{W} \\
\mathbf{W} \\
\mathrm{W} \\
\mathrm{Al} \\
\mathbf{W} \\
\mathbf{W} \\
\mathbf{W} \\
\mathbf{W} \\
\mathbf{W} \\
\mathbf{W} \\
\mathbf{W}\end{array}$ & $\begin{array}{l}\mathrm{Al} \\
\mathrm{W} \\
\mathrm{Mg} \\
\mathrm{Mg} \\
\mathrm{Mg} \\
\mathrm{Mg} \\
\mathrm{Mg} \\
\mathrm{Mg} \\
\mathrm{Mg} \\
\mathrm{Mg} \\
\mathrm{Al} \\
\mathrm{Al} \\
\mathrm{Cu} \\
\mathrm{Al}\end{array}$ & $\begin{array}{c}1.44 \pm 0.02 \\
1.543 \pm 0.02 \\
2.471 \pm 0.05 \\
1.995 \pm 0.03 \\
1.750 \pm 0.02 \\
1.400 \pm 0.02 \\
1.488 \pm 0.02 \\
2.492 \pm 0.05 \\
2.295 \pm 0.04 \\
2.086 \pm 0.03 \\
2.455 \pm 0.05 \\
2.346 \pm 0.04 \\
2.492 \pm 0.05 \\
2.507 \pm 0.04\end{array}$ & $\begin{array}{l}9.8 \pm 0.2 \\
15.2 \pm 0.3 \\
25.7 \pm 0.7 \\
20.0 \pm 0.4 \\
17.4 \pm 0.4 \\
13.7 \pm 0.3 \\
10.0 \pm 0.2 \\
25.8 \pm 0.6 \\
22.2 \pm 0.6 \\
21.0 \pm 0.5 \\
29.3 \pm 0.7 \\
27.5 \pm 0.6 \\
29.6 \pm 1.0 \\
30.2 \pm 0.5\end{array}$ & $\begin{array}{c}4390 \pm 500 \\
3590 \pm 200 \\
2190 \pm 200 \\
2950 \pm 200 \\
\mathrm{~b} \\
3240 \pm 200 \\
4210 \pm 200 \\
2930 \pm 200 \\
3270 \pm 200 \\
2620 \pm 200 \\
2030 \pm 200 \\
2400 \pm 200 \\
2930 \pm 200 \\
2883 \pm 200\end{array}$ & $\begin{array}{c}12 \pm 4 \\
4.7 \pm 0.5 \\
56 \pm 6 \\
5.8 \pm 0.6 \\
- \\
2.5 \pm 0.3 \\
6.4 \pm 0.6 \\
55 \pm 6 \\
3.5 \pm 0.4 \\
2.3 \pm 0.2 \\
780 \pm 80 \\
41 \pm 4 \\
30 \pm 3 \\
22 \pm 2\end{array}$ & $\begin{array}{c}\text { none } \\
\text { small } \\
\text { small } \\
\text { severe? } \\
- \\
\text { moderate } \\
\text { severe } \\
\text { small } \\
\text { small } \\
\text { small } \\
\text { moderate } \\
\text { none } \\
\text { severe } \\
\text { small }\end{array}$ & $\begin{array}{l}1 \\
1 \\
3 \\
2 \\
- \\
1 \\
1 \\
2 \\
2 \\
2 \\
3 \\
2 \\
2 \\
2\end{array}$ \\
\hline
\end{tabular}

IFE, interface flash effect.

a $\mathrm{W}$, tungsten; $\mathrm{Al}$, aluminum; $\mathrm{Cu}$, copper; $\mathrm{Mg}$, magnesium.

b No light emitted.

100 ns. Gate times during an experiment are typically 300$500 \mathrm{~ns}$ and are normally timed to occur while the shock wave is near the center of the sample.

$A$ portion of the beam is focused by a series of lenses into a TRW framing camera which images the sample during shock propagation. The framing camera allows up to three 100-500 ns exposures to be taken during propagation of the shock wave.

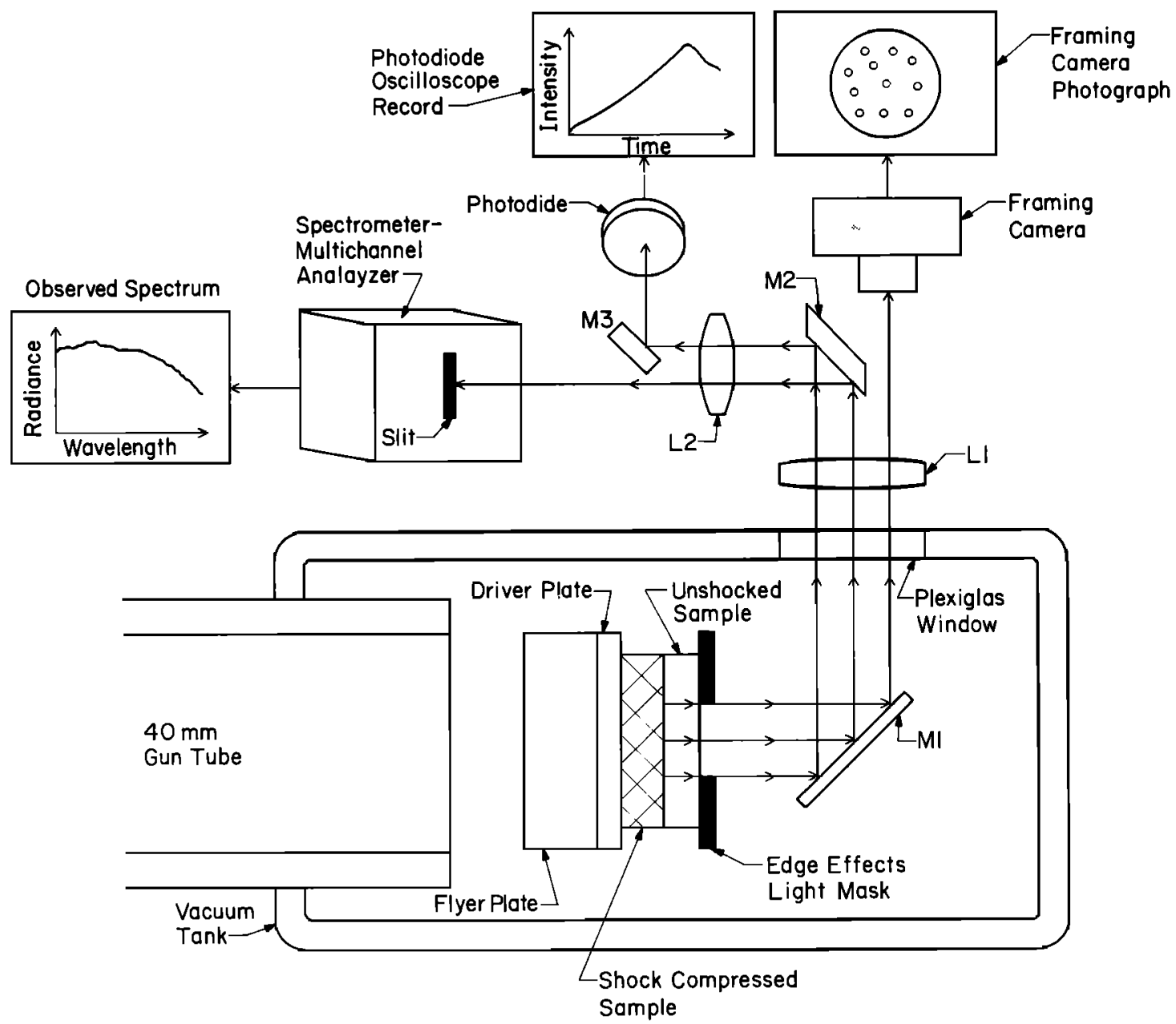

Fig. 3. Shock radiation experimental configuration. 
During setup of each experiment, the image of the fused silica sample is focused on the spectrometer slit (Figure 4). Magnification of the image was approximately $1: 1$; however, this varied due to movement of the experiment chamber between successive experiments resulting in slightly different light paths which changed the focus. The image of the unmasked region of the sample was $\sim 15 \mathrm{~mm}$ in diameter and covered the $13-\mathrm{mm}$ high slit in the spectrometer.

Calibration of the spectrometer was accomplished before each experiment with a standard of spectral radiance (Optronics model 550, lamps IR-30 and IR-159). As small variations in current affect the radiance of the lamp considerably, current to the lamp was monitored to $\pm 0.03 \%$.

Spectral radiances of the calibration lamp were supplied by the manufacturer (Figure 5). However, the spectrometer required a value of spectral radiance over each of the 500 channels representing a different wavelength. Appropriate values were supplied by a fit of the given calibration lamp radiances to the linearized Planck gray body radiation law (equation (3)). The curves through the known radiances represent the equivalent gray body function for the lamp, this function was used in the reduction of the spectrometer data. The maximum error introduced by use of the fits shown is below $2 \%$ over the most sensitive spectrometer wavelengths (550$750 \mathrm{~nm}$ )

During calibration, all controllable variables (light path, spectrometer delay (200-700 ns), and spectrometer gate (300-500 ns)) were identical to those of the experiment in order to reduce errors. A camera shutter set at $1 / 500$-s exposure was used to trigger the system and to limit the amount of dark current into the spectrometer. Based upon tests using longer shutter open times, dark current radiance errors were found to be less than $5 \%$ of the magnitude and independent of wavelength.

Light levels from the fused quartz samples during an experiment were less than $25 \%$ the level of light emitted by the calibration lamp. Since the CCD spectrometer had a limited light level sensitivity range, low light levels resulted in large signal to noise problems, whereas high light levels could saturate the detector. Coordination of the calibrated light level with the expected light level for an

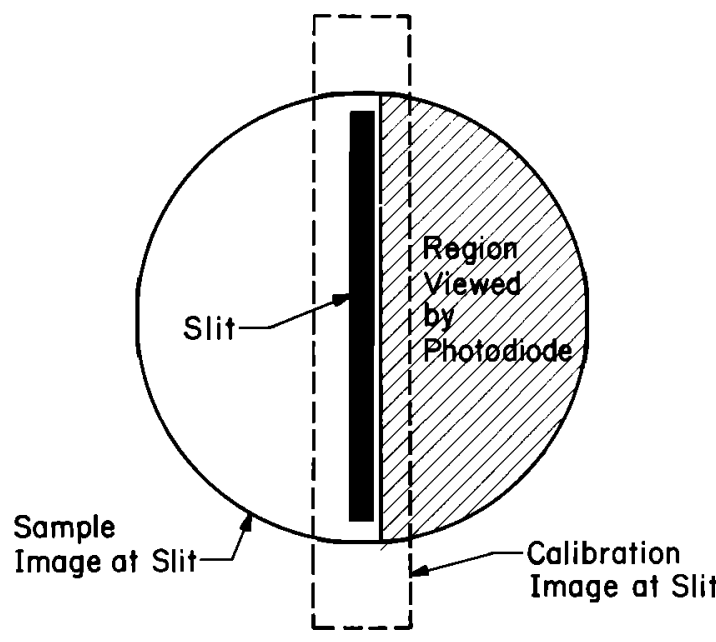

Fig. 4. View of spectrometer slit. Images of fused quartz sample and filament of calibration ribbon lamp shown. Light accumulated by spectrometer during experiment originates only within the region of the sample which is focused directly over the slit. Region of sample to right of slit is reflected by a mirror to the photodiode.

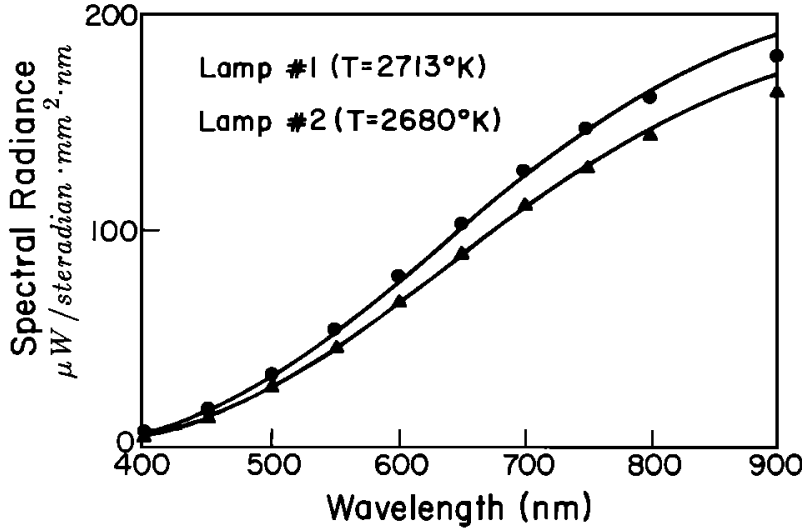

Fig. 5. Spectral radiances of calibration lamps. Triangles, lamp 1 (2713 K); circles, lamp 2 (2680 K).

experiment involved maximizing the amount of light arriving at the spectrometer during calibration with neutral density filters. The spectral characteristics of the neutral density filters were carefully accounted for by taking a number of tests of various light paths through the system.

The wavelength function of the spectrometer was determined by use of common spectral lines [Weast, 1982] of hydrogen $(656.2 \mathrm{~nm})$, helium $(587.6 \mathrm{~nm}$, $667.8 \mathrm{~nm}, 706.5 \mathrm{~nm})$, oxygen $(777.3 \mathrm{~nm}, 844.6 \mathrm{~nm})$ and mercury $(578.6 \mathrm{~nm}, 546.1 \mathrm{~nm})$. Low intensities from the standard gas lamps made calibration at experimental gating times $(-300 \mathrm{~ns})$ difficult; several tests were conducted for each lamp to reduce the signal to noise ratio. The accuracy of the wavelength function versus detector channel varied with wavelength and was inversely proportional to the density of standard lamp lines used in a given region of the spectrum; the maximum uncertainty encountered in the positioning of the spectral lines was approximately $3 \mathrm{~nm}$. Curvature of the vidicon intensifiers results in a variation of the wavelength interval per spectrometer channel which was, on average, $\sim 0.8$ $\mathrm{nm} /$ channel.

A single photodiode was used to obtain a record of light intensity versus time during the shock wave experiments. Output of this photodiode was simultaneously recorded with oscilloscopes and a LeCroy transient recorder sampling every $10 \mathrm{~ns}$. The photodiode and the spectrometer view different but adjacent areas of the sample (Figure 4).

\section{Data Reduction}

The observed number of counts at each spectrometer channel is proportional to the time-integrated intensity of the emitted radiation at the given wavelength. To obtain a spectrum, the raw data in counts were multiplied by a conversion factor relating spectral radiance intensity to number of counts derived from the calibration procedure (Figure 6). The temperatures of the standard lamps are approximately $2700 \mathrm{~K}$; the calibration factor thus is very sensitive to errors toward the red and violet ends of the observed spectral range.

The determination of shock temperatures from the observed spectra assumes that (1) the material radiates as a Planck gray body, (2) the emissivity of the material under shock compression is independent of wavelength, and (3) the temperature range of the experiment is such that a Wien's law spectral radiance distribution may be used. Assumptions 1 and 2 are based on the shape of the observed fused quartz spectra which, in general, are indicative of a thermal radiation: no line or band emissions are noted, 

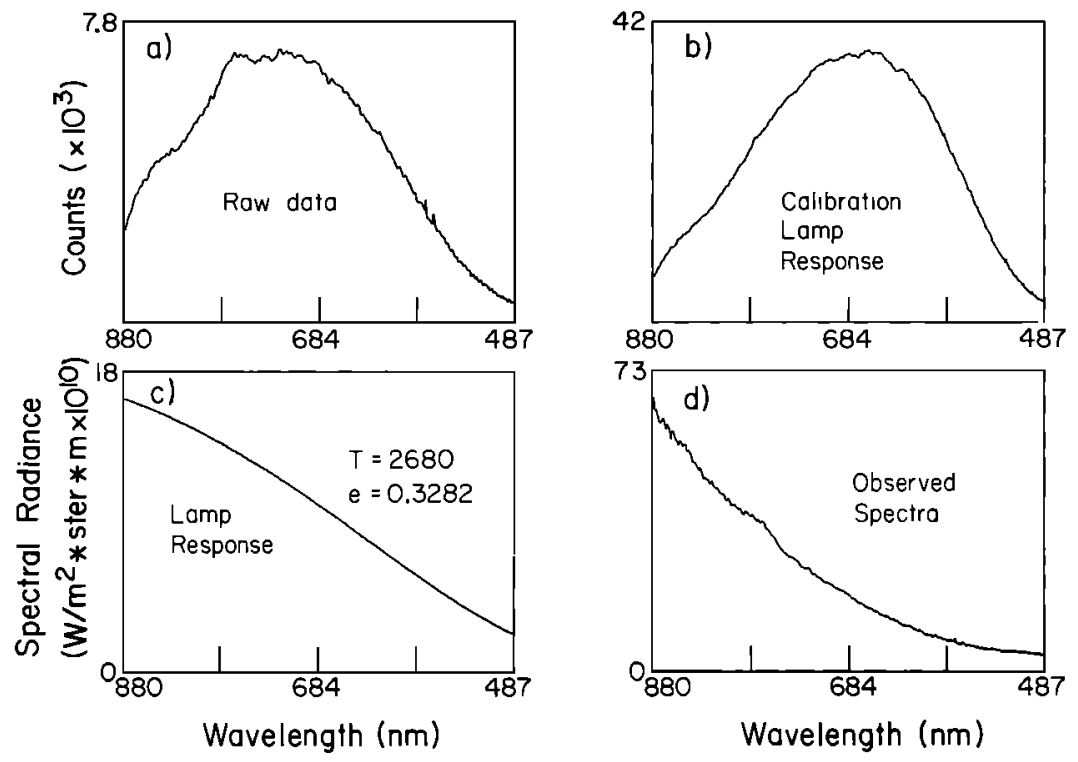

Fig. 6. (a) Raw data: response of spectrometer during experiment. (b) Spectrometer response to calibration lamp. (c) Output of spectral radiance lamp. (d) Observed spectra derived from Figures 6a-6c.

and the spectra monotonically decrease from the infrared to the ultraviolet. The complete Planck gray body function is given by

$$
R=\frac{\varepsilon c_{1}}{\lambda^{5}\left(\exp \left(c_{2} / \lambda T\right)-1\right)}
$$

where $R$ is the spectral radiance, $\varepsilon$ is the emittance, $T$ is the temperature of the emitting body, $\lambda$ is the given wavelength, and $c_{1}$ and $c_{2}$ are constants with values of $1.191 \times 10^{-16} \mathrm{Wm}^{2} / \mathrm{sr}$ and $0.01438 \mathrm{mK}$, respectively. For assumption 3 it is presumed that the simplification of equation (1), given by the Wien's gray body function:

$$
R=\frac{\varepsilon c_{1}}{\lambda^{5} \exp \left(c_{2} / \lambda T\right)}
$$

is justified in order to facilitate linearization of the formula. Errors introduced by use of this formula are larger for higher temperatures and longer wavelengths; however, for the temperature range encountered in the experiments (2000$4500 \mathrm{~K})$ and for the range in wavelengths $(450-880 \mathrm{~nm})$ the maximum error is less than $2 \%$ and for most cases many orders of magnitude smaller. As a check on the validity of the linearized results, an iterative least squares routine was also implemented with the full Planck gray body formula; results were always within $50 \mathrm{~K}$ of the linearized version.

The linearized Wien's law is given by

$$
\ln \left(\frac{c_{1}}{R \lambda^{5}}\right)=\frac{c_{2}}{\lambda} \frac{1}{T}-\ln (\varepsilon)
$$

where $\ln \left(\mathrm{c}_{1} /\left(\mathrm{R} \lambda^{5}\right)\right)$ and $\mathrm{c}_{2} / \lambda$ are dependent and independent variables and a standard linear regression is then applied to find the slope $1 / T$ and intercept $-\ln (\varepsilon)$ which yield temperature and emittance, respectively.

Since data at either wavelength range extreme have a larger uncertainty due to the reasons mentioned above, each datum is relatively weighted by its corresponding raw data count (see Figure 6). The raw data function supplies a reasonable weighting scheme as it inherently accounts for both sensitivity of the system and spectral regions of maximum emission (i.e., lowest signal to noise ratio).

\section{Results}

Figure 7 shows the spectra observed for x-cut crystalline shots 611 and 615 at shock pressures of 10.6 and 7.6 $\mathrm{GPa}$, respectively. The shape of the spectra are greatly influenced by a nonthermal emission centered at approximately $500 \mathrm{~nm}$ and cannot be fit to a gray body curve. The shape of the spectra, however, is indicative of broadened line emission superimposed upon a gray body spectra. The determination of shock temperatures was the primary motivation for this study; further experiments on crystalline quartz were discontinued since in this pressure range the large nonthermal component of the x-cut quartz spectrum does not allow accurate temperature determination.

Brannon et al. [1983a] reported spectral and imaging data

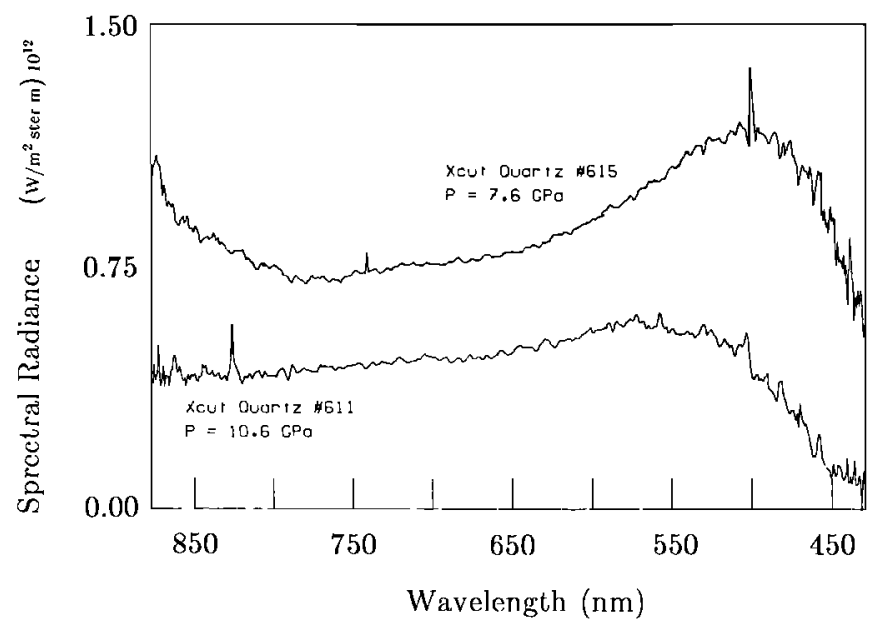

Fig. 7. Spectra observed for shots 611 and 615 for $x$-cut crystalline quartz. A large nonthermal component to the spectra centered near $500 \mathrm{~nm}$ makes temperature determination infeasible. 
for shocked crystalline quartz from 6 to $26 \mathrm{GPa}$. They also observed a nonthermal bandlike spectral feature with peaks at 400 and $600 \mathrm{~nm}$. Present observations displayed an emission at $500 \mathrm{~nm}$, the difference in data may be due to the higher wavelength resolution of this study. The sounce of this nonthermal radiation is unclear and may be related to photoluminescence or cathodoluminescence [Brannon et al., 1983b]. Since no nonthermal component was observed from fused quartz, the 500-nm crystalline quartz emission may be related to breaking of long-range crystalline order or the inherent piezoelectricity of quartz.

Another proposed explanation may be related to the production of the shock lamellae in crystalline quartz. Because fused quartz is a homogeneous, isotropic, amorphous material, it has no structural preferences, and probably no shock lamellae are produced. Conceivably, thermal radiation may be associated with the shear heating within microfaults (in both fused and crystalline quartz), and nonthermal radiation could arise from the formation of the diaplectic glass within the shock lamellae (in crystalline quartz only).

The framing camera photograph consists of two exposures of shot 634 under shock compression (Figure 8), each of $100 \mathrm{~ns}$ duration and separated by $300 \mathrm{~ns}$. The first exposure was initiated $50 \mathrm{~ns}$ after entry of the shock wave into the sample. The corresponding photodiode record for 634 (Figure 12) commences with zero intensity at the entry of the shock wave into the fused quartz sample and builds in a linear fashion with time. This furnishes convincing evidence that the bright spots observed in the photograph originated within the compressed fused quartz and not at the driver-sample interface.

Figures 9, 10, and 11 and Table 1 present the spectra and related data for the present experiments on fused quartz. The best fit Planck gray body function is plotted through each spectrum. It should be noted that although we believe the observed fused quartz spectra to be of a thermal nature, the possibility exists that the spectra could be contaminated by nonthermal emissions as observed in the two single-crystal quartz experiments. This possibility is most apparent for shots 634 and 688 at shock pressures near $10.0 \mathrm{GPa}$ which yield formal standard deviations of the gray body temperatures of $38.8 \mathrm{~K}$ and $57.8 \mathrm{~K}$, respectively, and whose spectra decay rapidly toward the infrared wavelengths. Except for the low signal to noise spectra of shot 635 with a standard deviation of $57.1 \mathrm{~K}$, the remainder of the formal standard deviations derived from the least squares routine yield temperature uncertainties less than $\pm 30 \mathrm{~K}$, suggesting that these spectra are indeed primarily of a thermal origin. However, we believe these uncertaities to be unrealistically small and, on the basis of experience with the data, suggest an uncertainty of $\pm 200 \mathrm{~K}$ is more appropriate for the observed temperatures.

Figure 9 are the spectra obtained in the pressure range from 10 to $16 \mathrm{GPa}$ which is the region of permanent densification along the fused quartz Hugoniot. Unexpectedly, the temperatures are highest in this lowest of pressure ranges studied. As noted, shots 688 and 634 display a marked drop in intensity at lower wavelengths (less than $450 \mathrm{~nm}$ ) which may be attributed to poor spectrometer sensitivity in this wavelength region and reinforces the importance of weighting the data in least squares fits of equation (3). This low sensitivity effect may also be seen at the high wavelengths where there is a noticeable increase in the signal to noise ratio. The level of noise for shot 635 is particularly high as in this experiment most of the light was routed to the TRW framing camera.

Figure 10 displays spectra over the pressure range of 16$30 \mathrm{GPa}$, the spectra in Figure 10 are included on the basis of their emittance and their shock pressure within the mixed phase region of fused quartz. The two spectra in Figure 11 for shots 708 and 684 are within the same
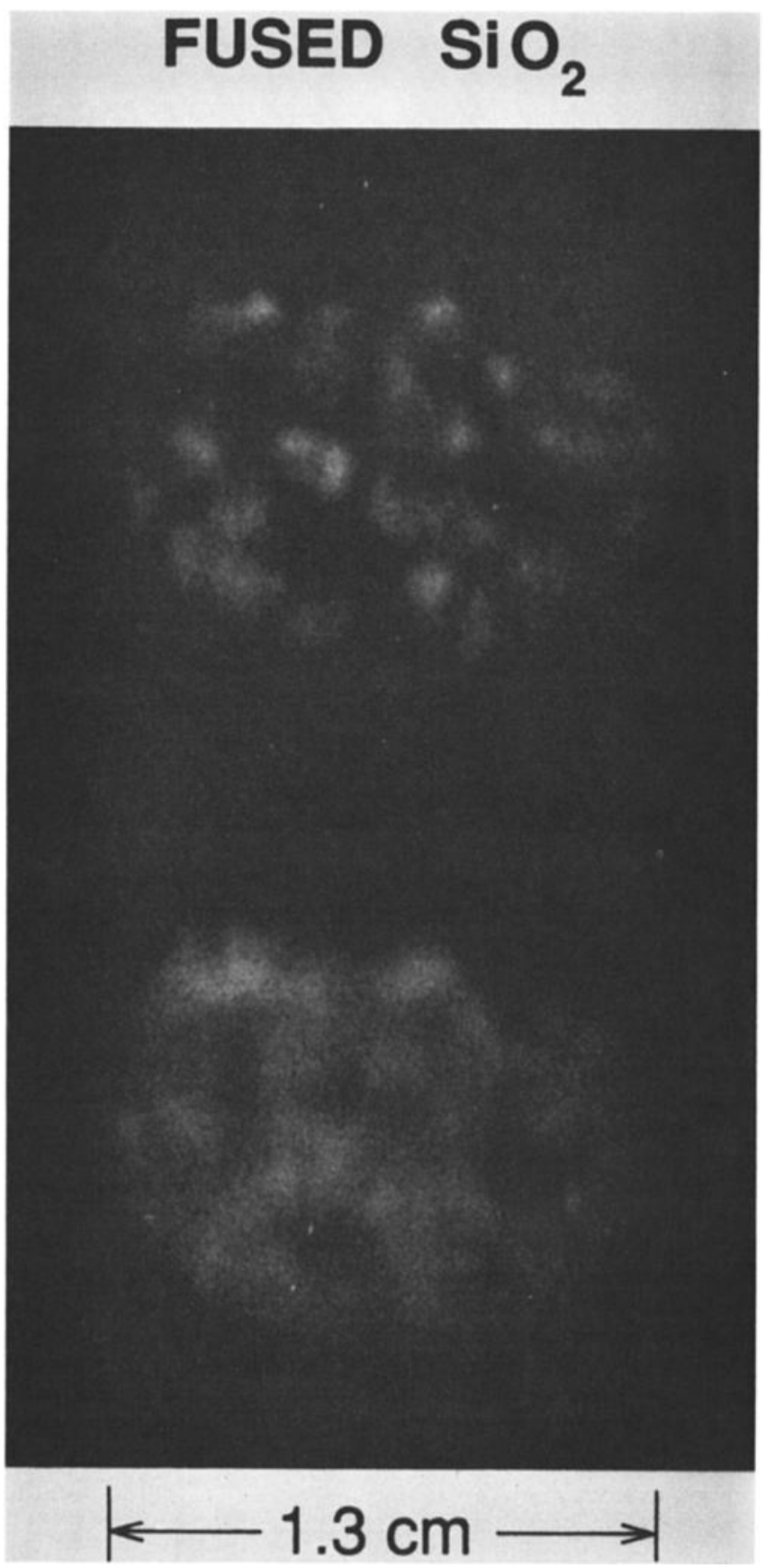

Fig. 8. Framing camera photograph for fused quartz shot 634 at $9.8 \mathrm{GPa}$. Two exposures each of $100 \mathrm{~ns}$ duration and separated by $300 \mathrm{~ns}$ are shown.

pressure range, but both had emittances an order of magnitude larger and lower temperatures than the spectra of Figure 10.

Photodiode records for this series of experiments are shown in Figure 12. These are the combined results from both the oscilloscope and transient recorder data. Since the photodiode supplies only a qualitative response, all intensities have been normalized. The response of the photodiode is dependent upon the amount of light allowed to reach the spectrometer, the calibration lamp therefore gives a response of 200-700 $\mathrm{mV}$ and the typical peak amplitude during an experiment ranges from 100-300 mV. It should be noted that the photodiode and the spectrometer view different but 
FUSED QUARTZ PERMANENT DENSIFICATION REGION
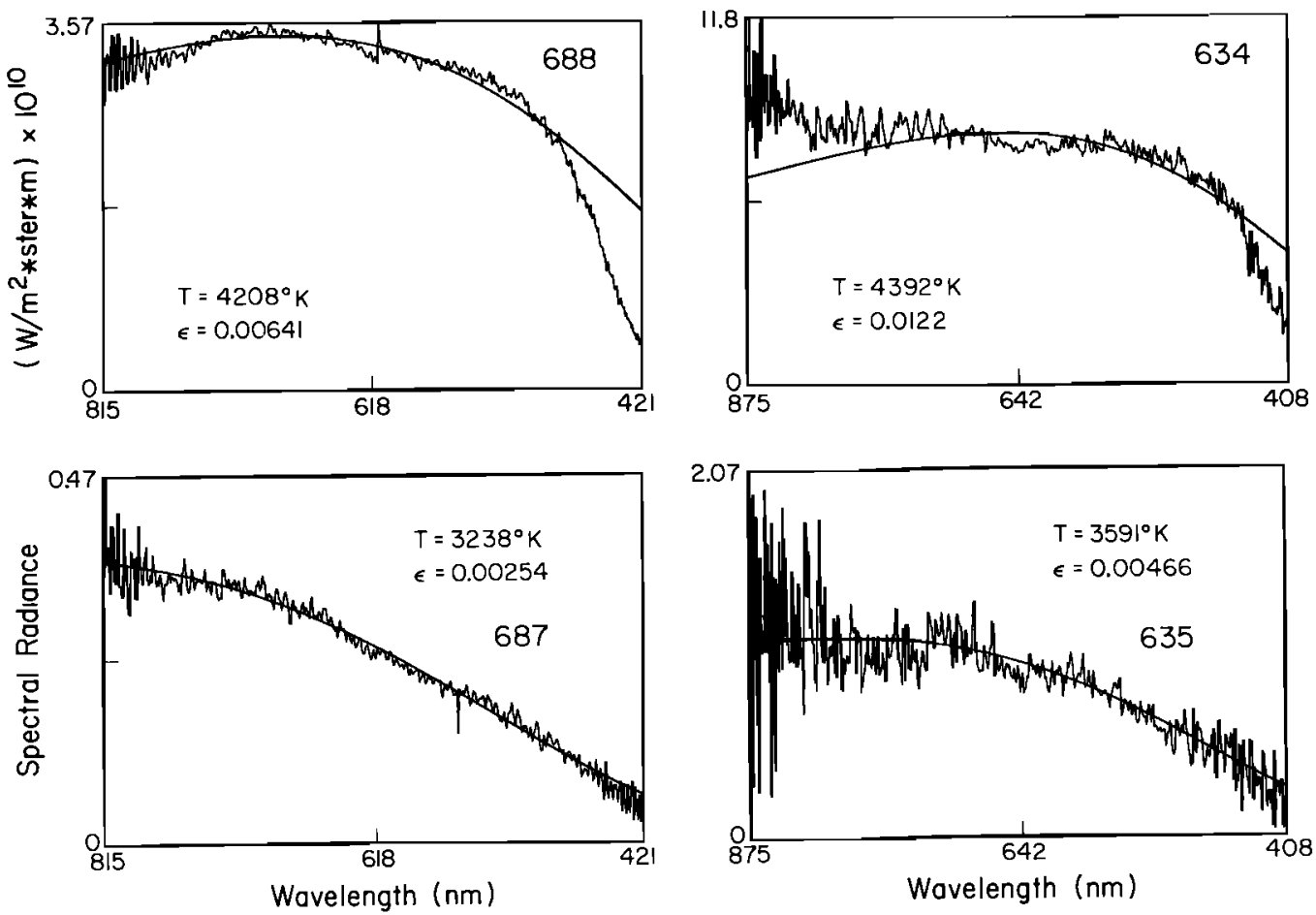

Fig. 9. Observed spectra from fused quartz shocked between 9.8 and $16 \mathrm{GPa}$ (field 1 in Figures $13 \mathrm{a}$ and 14).

adjacent regions of the sample during an experiment (Figure 4). The photodiode records are discussed below.

It should also be noted that shot 686 at $17.4 \mathrm{GPa}$ had no observable light emitted during the accumulation time of the spectrometer. Additionally, the photodiode recorded essentially no intensity until 500 ns after entry of the shock wave into the sample. This is followed by a large flash when the shock wave reaches the free surface of the sample at approximately $1 \mu \mathrm{s}$.

Least squares temperatures fit to equation (3) for the above spectra are plotted in Figure 13, and the corresponding emittances versus pressure are plotted in Figure 14 and are given in Table 1.

The range of the estimated Hugoniot temperatures of fused quartz is shown in Figure 13. The high estimate is that of Kondo and Sawaoka [1981], and the low estimate is that of Wackerle [1962]. We believe these estimates to be extreme. It is difficult to calculate the continuum shock temperature of fused quartz under shock compression by the method of Ahrens et al. [1969] because of the lack of knowledge of an accurate isentropic equation of state of fused quartz above $3 \mathrm{GPa}$ and of the correct thermodynamic parameters. For example, fused quartz has an extremely low thermal Gruneisen parameter [Stacey, 1977] of 0.012 at 1 bar pressure due to its small coefficient of thermal expansion. This may not remain small with increasing pressure. Another complicating factor is the anomalous compression of fused quartz; the bulk modulus of fused quartz is known to decrease to approximately $2.3 \mathrm{GPa}[$ Kondo et al., 1981] and increases above this pressure [Meade and Jeanloz, 1987].

\section{Discussion}

\section{Heterogeneous Deformation in Fused Quartz}

New evidence for the heterogeneous deformation of fused quartz under shock compression is supplied by the framing camera photograph of shot 634 (Figure 8) in which a pattern of bright regions or hot spots is seen in agreement with earlier studies [Brooks, 1965; Brannon et al., 1983b]. The number of regions grows with time, i.e., with the distance that the shock wave has propagated into the fused quartz. Additionally, these regions persist and grow for at least $500 \mathrm{~ns}$ : the time spanning this set of exposures. Further, that these localized hot zones originate in the fused quartz is proven by the simultaneously recorded photodiode record (Figure 12). No sample-driver interface flash is seen; light intensity commences at zero when the shock wave enters the fused quartz and grows linearly with time, suggesting a constant production of shear bands with time as the shock propagates into the sample.

\section{Interpretation of Temperatures and Emittances}

Figure 13a displays the observed shock temperatures versus pressure. The estimated fields of silica melt $(\mathrm{L})$, stishovite $(\mathrm{St})$, coesite $(\mathrm{Co})$, crystalline quartz $(\mathrm{Q})$, and cristobalite $(\mathrm{Cr})$ are shown. The stability fields below 5 $\mathrm{GPa}$ are from Jackson [1976]; phase boundaries are from Davies [1972] and Jeanloz and Thompson [1983]. Temperature measurements above $30 \mathrm{GPa}$ of Sugiura et al. [1982] are also included as well as the calculated fused quartz shock continuum temperatures [Kondo and Sawaoka, 1981; Wackerle, 1962] as discussed above.

The following observations are made from this plot:

1 Temperature appears to decrease with pressure from over $4400 \mathrm{~K}$ at $10 \mathrm{GPa}$ to approximately $3000 \mathrm{~K}$ at 30 GPa. This decrease levels off above $16 \mathrm{GPa}$.

2 Observed color temperatures exceed those calculated for the continuum by nearly $1000 \mathrm{~K}$.

3 Three anomalous shots above $25 \mathrm{GPa}$ exhibit lower temperatures. 
FUSED QUARTZ MIXED PHASE REGION
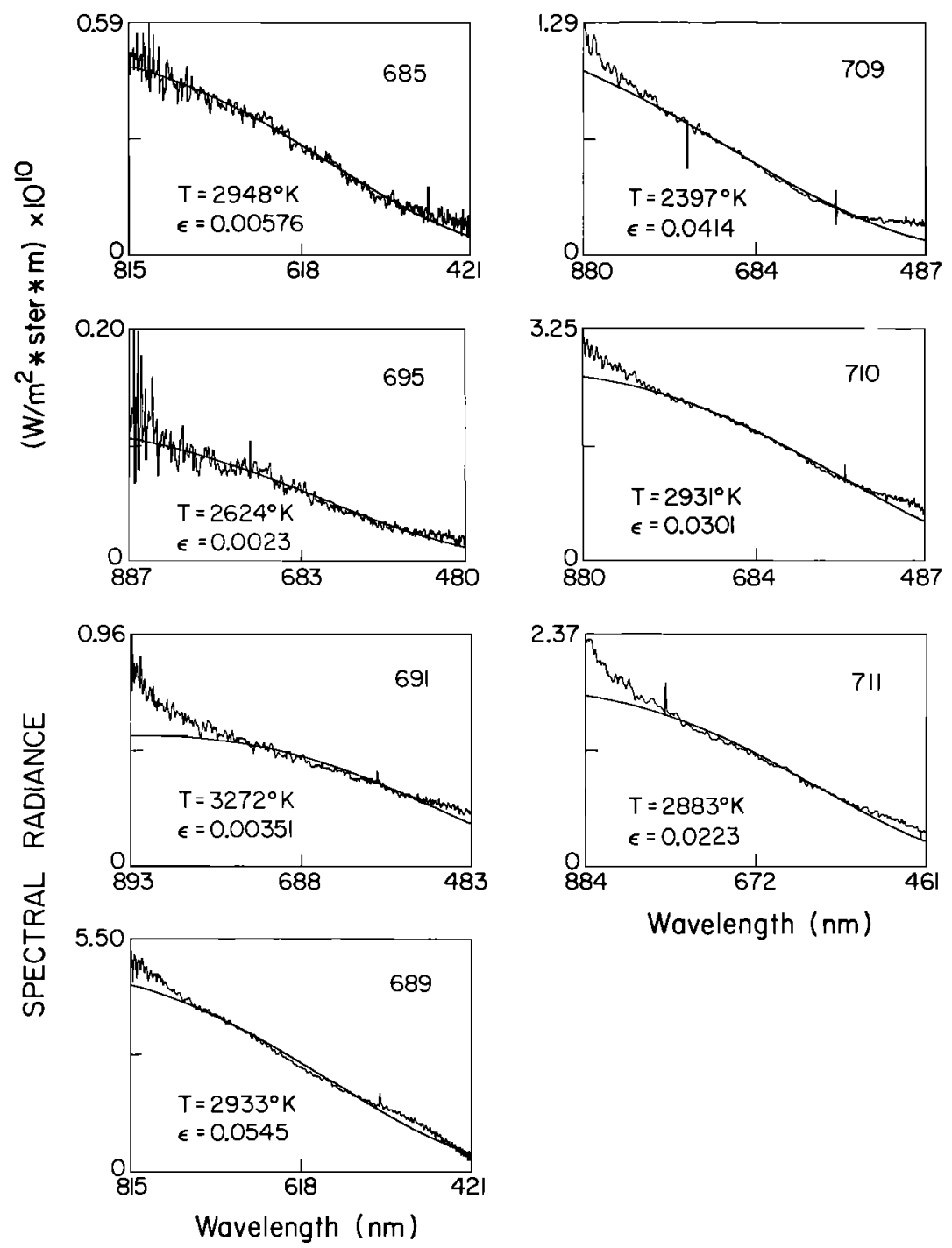

Fig. 10. Observed spectra from fused quartz shocked in the mixed phase region (20-30 GPa) (field 2 in Figures 13a and 14).

There is an approximate dependence on emittance on pressure (Figure 14). Below $25 \mathrm{GPa}$ all emittances are less than 0.02. A threshold pressure appears to be reached above $25 \mathrm{GPa}$ where the emittance increases by at least an order of magnitude. Finally, two shots have emittances which are almost those of a blackbody. The emittance may be an approximate measure of the areal density of the localized zones of deformation; the density of the features of heterogeneous deformation increases with pressure [Ashworth and Schneider, 1985]. The approach of the emittance toward unity at the higher pressures may signal the onset of a regime of a more homogeneous shock deformation reached when the density of microfaults becomes high.

The observation of temperatures greatly in excess of the estimated continuum temperatures and corresponding low emittances suggest that fused quartz undergoes a process of heterogeneous shock deformation as also suggested by similar shock wave experiments of crystalline halite, calcite, and gypsum [Kondo and Ahrens, 1983a] and of potassium chloride, lithium fluoride, and periclase [Schmitt et al. 1986; Schmitt and Ahrens, 1983].
Based upon observations of the observed temperatures and emittances, the data have been divided between three fields, each of which is characterized by the type of shock deformation occurring, and the magnitude of the emittance.

The first field is within the pressure range of $10-16 \mathrm{GPa}$ which has been referred to as the permanent densification region of fused quartz [Sugiura et al. 1981]. The spectra within this field have low emittances (less than 0.015) and the highest temperatures $(3200-4400 \mathrm{~K})$ which decrease with increasing pressure. This anomalous behavior is not understood but appears to be related to the transformation to stishovite which commences near $7.5 \mathrm{GPa}$ at low temperatures as noted earlier. The high temperatures may be characteristic of the transformation at the initiation of the mixed phase region. This phenomenon has been more fully observed in crystalline $\mathrm{NaCl}$ over the $\mathrm{B} 1-\mathrm{B} 2$ solid phase transition region [Schmitt et al., 1988]. However, a direct analogy between $\mathrm{NaCl}$ and $\mathrm{SiO}_{2}$ may not be justified since the phase relations of $\mathrm{NaCl}$ are much simpler than those of $\mathrm{SiO}_{2}$ with a number of high-pressure solid phases.

On a speculative note, these high temperatures may be related to the large activation energy or energy barrier 
FUSED QUARTZ

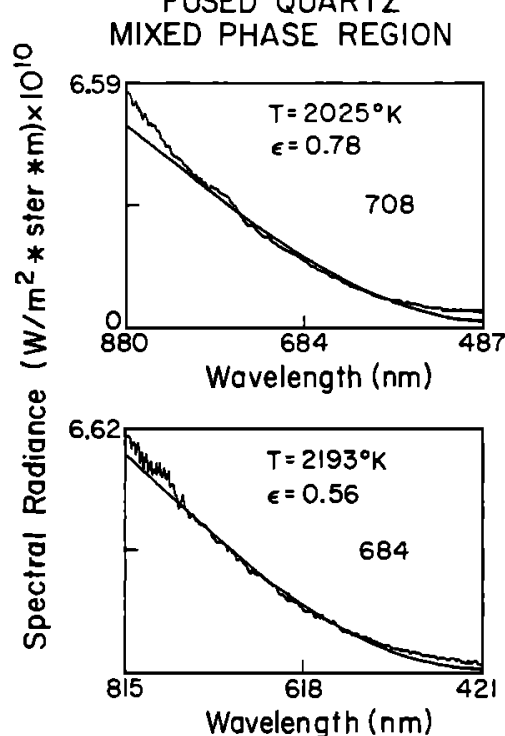

Fig. 11. Observed spectra from fused quartz undergoing homogeneous shock deformation based upon low temperatures and high emittances (field 3 in Figures 13a and 14).
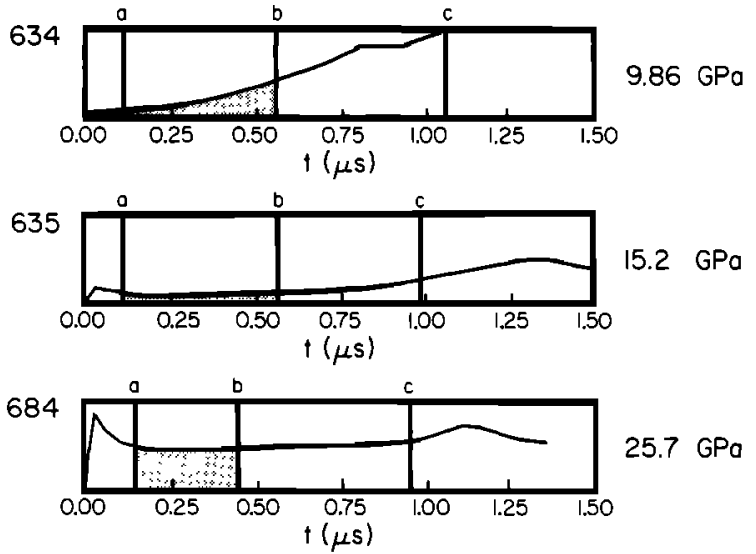

$25.7 \mathrm{GPo}$

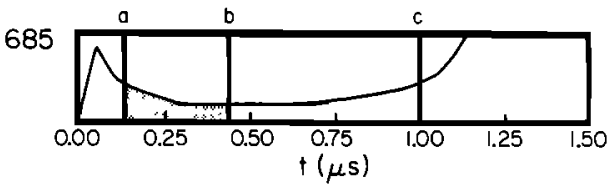

$20.0 \mathrm{GPa}$

686

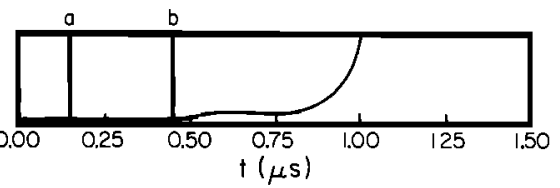

$17.4 \mathrm{GPo}$

687

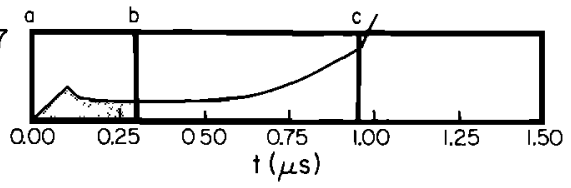

$13.7 \mathrm{GPa}$

688

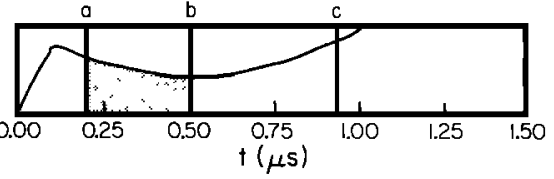

$\left(\sim 3.5 \times 10^{6} \mathrm{~J} / \mathrm{kg}\right.$ of $\left.\mathrm{SiO}_{2}\right)$ to the reconstructive quartz to stishovite transformation [Grady, 1980; Holm et al., 1967] which dictates the amount of energy required to initiate the transformation. Deposition of insufficient energy by the shock wave to activate the transformation must raise the temperature of the material. The maximum temperature rise $\Delta T$ may be estimated by the amount of energy required to activate the process $A$ divided by the heat capacity $C_{p}$ of the material or:

$$
\Delta T=\frac{A}{C_{p}}
$$

Using the values of activation energy and the heat capacity of Table 2, the maximum temperature rise before activation of the transformation is estimated to be approximately $4700 \mathrm{~K}$; this value is consistent with the observed radiative temperatures of $\sim 4400 \mathrm{~K}$ near $10 \mathrm{GPa}$. If the observed emittances $(\sim 0.01)$ near $10 \mathrm{GPa}$ yield the relative volume of material undergoing the phase transformation, then the process mentioned above requires approximately $10-15 \%$ of the total energy available in shock compressed fused quartz by the RankineHugoniot energy equation:

$$
\Delta \mathrm{E}=\frac{1}{2}\left(\mathrm{~V}_{0}-\mathrm{V}_{1}\right) \mathrm{P}_{\mathrm{h}}
$$
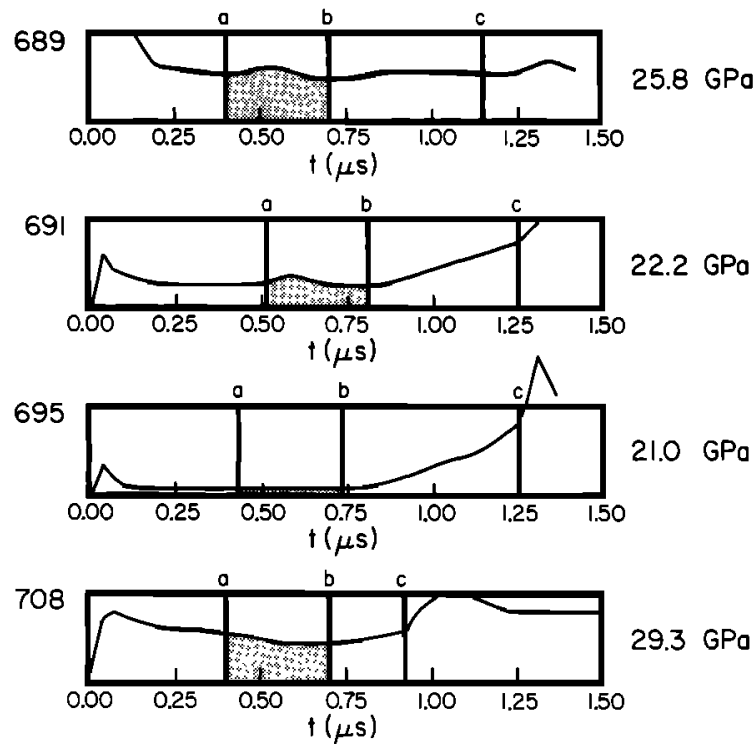

$29.3 \mathrm{GPO}$

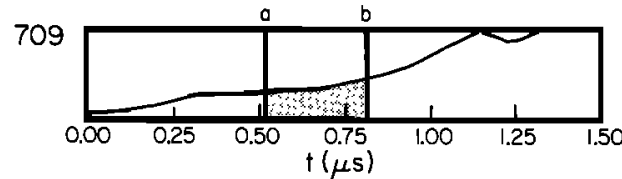

$27.5 \mathrm{GPo}$

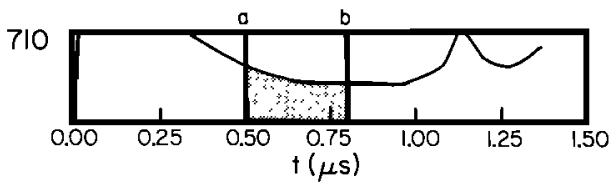

$29.6 \mathrm{GPa}$

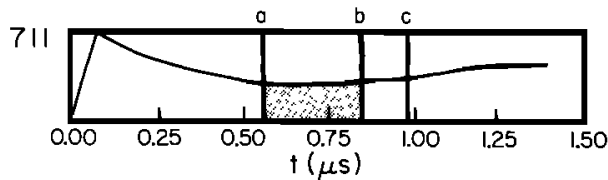

$30.2 \mathrm{GPo}$

Fig. 12. Normalized intensity versus time, fused quartz. Fiducials $a, b$, and $c$ represent times of initiation of spectrometer light accumulation, end of accumulation, and first shock wave arrival at sample free surface, respectively. 


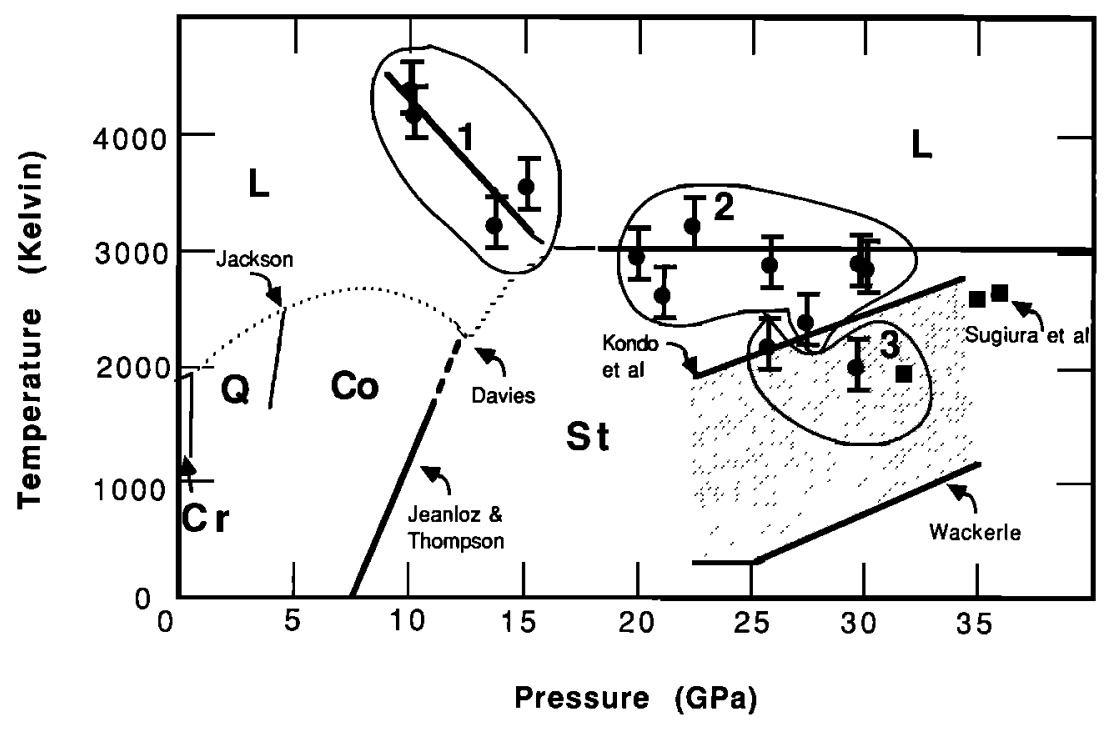

Fig. 13a. Fused quartz temperatures versus pressure. Data are separated into three fields: 1, 2, and 3, as in Figure 14. Coesite-stishovite-liquid triple point based on calculations of Davies [1972] and Jackson [1976]. Quartz-coesite line based on data of Holm et al. [1967]. Coesite-stishovite phase line from Jeanloz and Thompson [1983]. Estimated shock temperatures of Kondo and Sawaoka [1981] (K) and Wackerle [1962] (W). Shock temperature measurements of Sugiura et al. [1982] are solid squares. Estimated stability fields of silica melt $(\mathrm{L})$, stishovite $(\mathrm{St})$, coesite (Co), crystalline quartz $(\mathrm{Q})$, and cristobalite $(\mathrm{Cr})$ are shown.

where $\Delta \mathrm{E}$ is the internal energy change upon shock compression, $V_{0}$ and $V_{1}$ are the initial and final specific volumes, respectively, and $\mathrm{P}_{h}$ is the shock pressure.

Field 2 contains the shots which have low emittances (less than 0.1 ) and are within the mixed phase region of the fused quartz Hugoniot. The high temperatures and low emittances indicate a heterogeneous deposition of thermal energy within the fused quartz. These temperatures would represent the melting temperature of stishovite at high pressure. The melting temperature of stishovite between 20 and $30 \mathrm{GPa}$ is thus estimated to be $3000 \mathrm{~K} \pm 200$ $\mathrm{K}$. This melting temperature is independent of pressure to the degree of precision available in this experiment.

Lyzenga et al. [1983] measured shock temperatures in both fused and crystalline quartz between 60 and $140 \mathrm{GPa}$. At these pressures, silica is believed to be well into the stishovite phase (see earlier discussion of phase transformation in quartz). Based on their temperature measurements, Lyzenga and coworkers provided evidence for the melting of stishovite and obtained an hypothetical melting curve at high pressure (Figure 13b). The present data lie on or close to the proposed melting line of Lyzenga et al. [1983] thus supporting the present hypothesis that the melting temperatures are observed.

Field 3 contains the two high emittance (near black body)/lower temperature data indicative of the onset of a more homogeneous deformation. These temperatures are close to those observed by Sugiura et al. [1982] by a similar technique above $30 \mathrm{GPa}$. Higher emittances appear to indicate more homogeneous shock deformation according to Lyzenga and Ahrens [1980], who report emittances $>0.75$ and in most cases near unity for fused quartz shocked to pressures in excess of $70 \mathrm{GPa}$. Lyzenga et al. [1983] further demonstrate the homogeneity of the deformation at these pressures in a streak camera record of alpha quartz at $106.5 \mathrm{GPa}$ which displays uniform emittance.

The reason for the overlap of the pressure ranges of fields

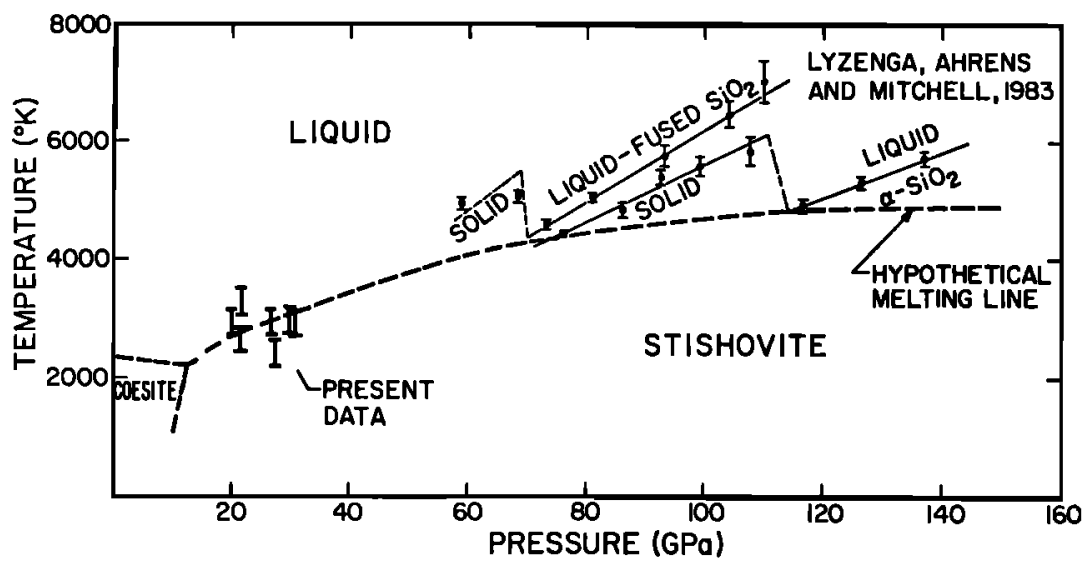

Fig. 13b. Temperature versus pressure plot to include the data of Lyzenga et al. [1983] and their proposed melting line. Plot contains only data from field 2 . 
FUSED QUARTZ

EMITTANCE VS PRESSURE

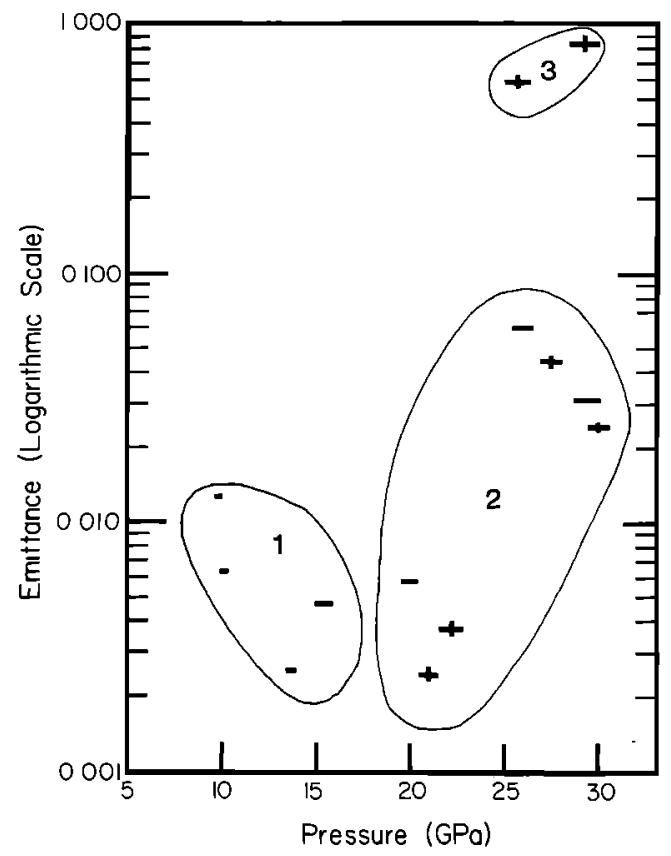

Fig. 14. Log (gray body emittance) versus pressure. Field numbers are the same as in Figure 13a.

2 and 3 is not known and may be related to differences in sample preparation or due to the inherent variation in fused quartz samples. Within a given sample of fused quartz the variation of the index of refraction, which is a measure of density, can be as high as $5.0 \times 10^{-6}$ (HeraeusAmersil specifications). Also, small bubbles and inclusions do exist within the fused quartz; differences in their density may result in the observed shot to shot variations.

\section{Photodiode Records}

Ideally, the present experiments are designed to prevent light generation at the driver-fused quart $z$ interface. Because of the opaque silver film, detected light originates only within the shocked fused quartz. The production of hot shear deformation zones appears to be nearly constant with time. The hot zones persist for a time scale of the order of the transit time of the material [Grady, 1980], and the absorption characteristics of the shock compressed material appear to be nearly identical to the as yet unshocked material. This results in a linear increase in the emitted intensity with time [Boslough, 1985]; the ideal photodiode record would therefore have a nearly linear increase in intensity with the propagation of the shock wave into the sample. Such behavior is displayed by shots 634 and 709 at pressures of 9.8 and $27.5 \mathrm{GPa}$, respectively.

However, many of the experimental photodiode records (Figure 12) display a more complicated structure which includes evidence of some fused quartz sample-driver interface heating (coinciding with entry of the shock wave into the sample). This problem has been addressed by Urtiew and Grover [1974], Grover and Urtiew [1974], Boslough [1985], and Svendsen et al. [1986], who demonstrate that this is a potential problem with measurements of shock temperatures in clear or translucent materials. Briefly, their model involves deposition of a quantity of heat at the interface due to collapse of micron scale gaps between the driver and sample. This heat results in the production of high temperatures at the interface which decay inversely with $(\kappa t)^{1 / 2}$, where $\kappa$ is the thermal diffusivity of the metal driver which is assumed to have a higher thermal conductivity with respect to the sample. The observed photodiode records display this behavior. Note that the rise time of the photodiode due to its amplification is approximately $50 \mathrm{~ns}$. Thus because of the finite rise time of the photodiode electronics, the peak signal is nearly coincident with the entry of the shock wave into the sample.

Some photodiode signals are thus a superposition of the interface gap flash and the light produced within the fused quartz [Boslough et al., 1986] (Figure 15). In Table 1 , severe contamination occurs when spectrometer accumulation occurs primarily during the time of decreasing photodiode intensity due to interface cooling. Moderate contamination occurs when the gap flash is low amplitude and part of the accumulation time overlaps with decreasing photodiode intensity. Contamination is considered to be small when accumulation time occurs in an increasing or almost level portion of the light intensity signal observed after the interface temperature has decayed to the continuum temperature of the shocked sample. In Table 1, none refers to no gap flash contamination.

Although we expected that the potential effect of gap flashes on the measured temperatures might be very deleterious, we found surprisingly that shots at nearly the

a)

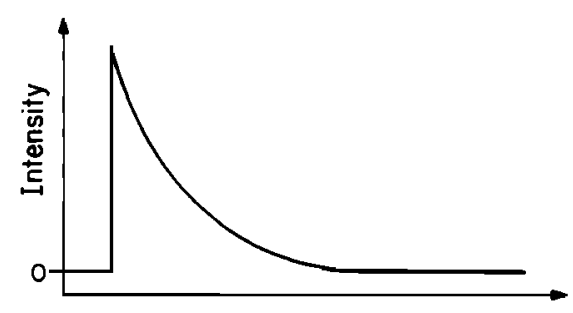

b)

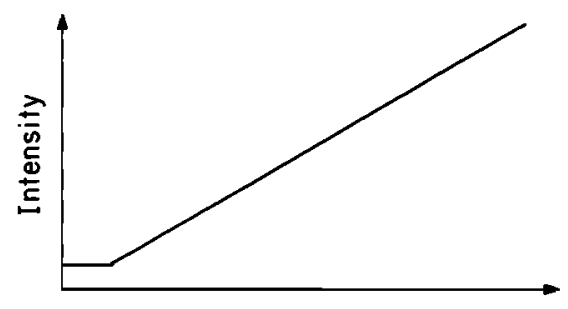

c)

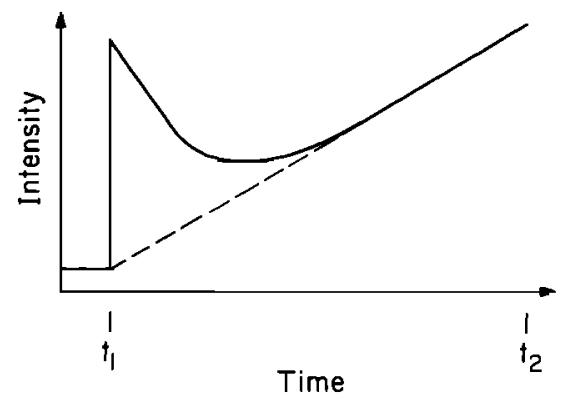

Fig. 15. (a) Hypothetical photodiode record assuming light originates only at driver-sample interface due to heating. (b) Photodiode record assuming light originates only from features of heterogeneous deformation within the sample, (c) Photodiode record obtained by superposition of records in Figures $15 \mathrm{a}$ and $15 \mathrm{~b}$. Figure $15 \mathrm{c}$ is similar to those observed in the experiments. 
TABLE 2. Thermal Parameters Used in Calculations

\begin{tabular}{|c|c|c|c|}
\hline Symbol & Definition & Value & Reference \\
\hline$\overline{\mathrm{A}}$ & $\begin{array}{l}\text { activation energy of } \\
\text { alpha-quartz to stishovite } \\
\text { reconstructive transformation }\end{array}$ & $3.5 \times 10^{6} \mathrm{~J} / \mathrm{kg}$ & Grady [1980] \\
\hline $\mathrm{C}_{\mathrm{p}}$ & $\begin{array}{l}\text { heat capacity } \\
\text { density }\end{array}$ & $\begin{array}{l}753 \mathrm{~J} / \mathrm{K} \mathrm{kg} \\
2204 \mathrm{~kg} / \mathrm{m}^{3}\end{array}$ & $\begin{array}{l}\text { Weast }[1982] \\
\text { measured }\end{array}$ \\
\hline $\begin{array}{l}\mathrm{p} \\
\mathrm{k}\end{array}$ & $\begin{array}{l}\text { latent heat of fusion } \\
\text { thermal conductivity }\end{array}$ & $\begin{array}{l}2.37 \times 10^{5} \mathrm{~J} / \mathrm{kg} \\
1.38 \mathrm{~W} / \mathrm{m} \mathrm{K}\end{array}$ & $\begin{array}{l}\text { Weast }[1982] \\
\text { Weast }[1982]\end{array}$ \\
\hline$\kappa$ & thermal diffusivity $\left(\mathrm{k} / \mathrm{p} \mathrm{C}_{\mathrm{p}}\right)$ & $8.33 \times 10^{-7} \mathrm{~m}^{2} \mathrm{~s}^{-1}$ & calculated \\
\hline
\end{tabular}

same pressure yield similar temperatures regardless of the degree of gap flash contamination. For example, shot 634 at $9.8 \mathrm{GPa}$ (with no gap flash) and shot 688 at $10.0 \mathrm{GPa}$ (severe gap flash) gave temperatures in excess of 4000 $\mathrm{K}$ and similar emittances. Additionally, shots 710 and 711 at pressure of 29.6 and $30.2 \mathrm{GPa}$ with severe and small gap flashes, respectively, both gave temperatures near $2900 \mathrm{~K}$ and emittances between 0.2 and 0.3 . A buffering of the gap temperatures to the melting point of the compressed silica (via mechanisms similar to those proposed within the microfaults may be occurring). Another explanation may be related to the evolution of the shock wave with increasing penetration into the sample. Hayes and Graham [1978] calculate stress-time histories for an impact of quartz on quartz and assume that time dependent shear stress relaxation occurs. The energy density dissipated at a given depth within the sample decreases monotonically until a stable shock wave is formed, resulting in the production of higher deformation feature densities near the interface.

\section{Microfault Temperature Variation With Time}

The observed temperatures, which we here suggest to be at the temperature of the melt in the microfaults at shock pressure in excess of $20 \mathrm{GPa}$, could be dependent on the scale of the deformation features on account of heat conduction. Heinz and Jeanloz [1987] noted the effect of spatial variations in temperature upon measured radiative temperatures in melting experiments within high-pressure diamond cells. We now examine the conditions where the observed radiative temperatures will not represent the melting temperature in the microfault.

We use the theory for solidification of a dike emplaced in a body of cooler country rock [Turcotte and Schubert, 1982]. Consider the intial microfault created within the shock wave front zone as a layer of thickness $2 b$ of molten silica at the melting temperature for a given pressure. Initially, material within the shear band is assumed to be totally molten and at the melting temperature $T_{m}$. Material outside of the shear band is shock compressed solid at the cooler temperature $T_{0}$ which is nearly equal to the isentropic continuum temperature. In most cases, $T_{m} \gg T_{0}$. Cooling of the shear band and the release of the latent heat of fusion during freezing occur due to heat flow from the microfault zone at $\mathrm{T}_{\mathrm{m}}$ to the compressed solid at $\mathrm{T}_{\mathrm{o}}$ by phonon or radiative conduction.

The temperature $T$ in the solid is given as a function of $y$, the distance away from the interface, and time $t$ as

$$
\frac{T-T_{0}}{T_{m}-T_{0}}=\frac{\operatorname{erfc}(v)}{\operatorname{erfc}(-\Lambda)}
$$

where

$$
v=\frac{y}{2(k t)^{1 / 2}}
$$

and the constant $\Lambda$ for a given set of thermal parameters must be determined by numerical calculation in the transcendental equation:

$$
\frac{L(\pi)^{1 / 2}}{C_{p}\left(T_{m}-T_{0}\right)}=\frac{\exp \left(-\Lambda^{2}\right)}{\Lambda(1+\operatorname{erf}(\Lambda))}
$$

$T$ is the temperature as a function of time $t$ and position $y$ from the microfault. The liquid/solid shear band boundary is at $y=0$ for $t=0$. The $\kappa$ is the thermal diffusivity which is a function of the heat capacity of the material $C_{p}$, the coefficient of thermal expansion: $\alpha$, and the density of the material. $L$ is the latent heat of fusion of silica, and erf and erfe are the error function and 1-erf, respectively.

The above equations have been solved using thermodynamic parameters for fused silica (Table 2) and for differences between the melt in the shear band and the surrounding solid of $500 \mathrm{~K}, 1000 \mathrm{~K}$, and $2000 \mathrm{~K}$. Figure 16a illustrates the growth of a frozen layer of solid with time for varied temperature differences. Figure 16a illustrates that for an extreme temperature difference of $2000 \mathrm{~K}$ the solidified zone thickness is approximately $1.6 \mu \mathrm{m} 1 \mu \mathrm{s}$ after creation of the microfault. Figure 16b displays the temperatures profile with time for an initial temperature difference of $1000 \mathrm{~K}$. Radiation emitted from these cooler regions will have an effect on the spectra of the observed light. The magnitude of this effect is dependent on the ratio of the volume of the cooled temperature material to the volume of the initial melted material. At maximum, the time scale for these experiments is $1 \mu \mathrm{s}$ but spectra are obtained from light accumulated not more than 800 ns after entry of the shock wave into the sample. Figures $16 \mathrm{a}$ and $16 \mathrm{~b}$ therefore suggest that for a microfault of thickness of $10 \mu \mathrm{m}$, which is expected on the basis of shock recovery work on quartz [Gratz, 1984], this cooling by conduction and freezing will have little effect upon the observed temperatures. However, if the thickness of the microfault is $5 \mu \mathrm{m}$ or less the cooling will have a much greater effect on the observed spectra. A microfault of $5 \mu \mathrm{m}$ or less created early on in the shock experiment may freeze solid by the end of the experiment (Figure 17). The effect of this cooling on measured temperatures, however, is offset by the constant production of microfaults with time as the shock wave propagates through the sample. 
Solidified Zone Thickness vs. Time After Formation of Microfault

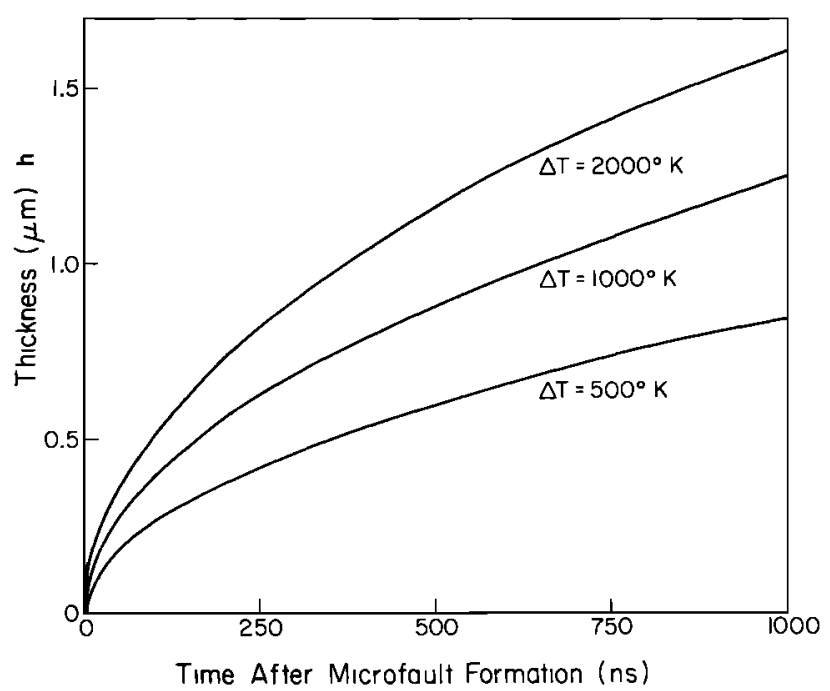

Fig. 16 a. Solidified zone thickness versus time after formation of microfault. $\Delta \mathrm{T}=\mathrm{T}_{\mathrm{m}}-\mathrm{T}_{\mathrm{O}}$.

This cooling and the resulting temperature gradients near a zone of microfault melt were further modelled in order to quantitatively evaluate their effects on the observed temperatures. The model assumes that a melt filled microfault of a width $2 b$ initiates with the entry of the shock wave into the fused quartz sample and this microfault propagates with the shock front. Also, immediately behind the shock front the temperature distribution of the microfault is assumed to have a boxcar form (as for time $t=0$ in Figure 17) which then decays with time due to conduction to a form similar to that of times $t 2$ and $t 3$ in Figure 17. Over the gate period of the recorder, the spectometer thus integrates radiative energy from newly formed lengths of the microfrault with nearly boxcar temperature distributions produced behind the propagating shock front as well as from the cooling, older lengths with more diffuse temperature distributions. Consequently, the total radiative energy arriving from the sample at a given spectrometer channel (which covers approximately $0.8 \mathrm{~nm}$ of wavelength) may be described as an integral of the thermal radiative energy, emitted in the three-dimensional shock compressed body of the sample over the gate period, which passes through the two-dimensional viewed region of the sample (Figure 4). We expect this thermal radiation to be characteristic of temperatures ranging from the shock continuum temperatures in regions for which microfault produced heat has not yet conducted to the material fusion temperature within the molten zones of the microfault. Under the assumptions that (1) all regions of the sample emit at the same emissivity regardless of temperature and that emissivity is independent of wavelength and temperature, (2) within the viewed zone of the sample the microfaults are uniform in both spacing (2Y) and width (2b), (3) the height of the microfaults is proportional to the distance the shock wave has propagated into the sample and is therefore a function of both time and shock wave velocity $U_{S},(4)$ the microfaults are planar and of a breadth much larger than both the height and width, (5) collection of radiant energy by the spectrometer commences at a time $t=t_{0}$ after entry of the shock wave into the sample at time $t=0$ and ends at time $t=t_{f}$ (i.e., the gate time is $t_{f}-t_{0}$ ), and (6) for all times, unshocked portions of the sample at room temperature emit insignificant thermal radiation over the spectral range of the spectrometer and may be ignored; the proportionality of the collected spectral energy $E \lambda$ is given by

$$
E_{\lambda} \quad \alpha \int_{t_{0}}^{t_{f}} \int_{-b}^{Y} \int_{0}^{Z} R_{\lambda}(T(y, z, t)) d z d y d t
$$

where $R \lambda$ is the spectral radiance given by equation (1) and which is a function of the spatially and temporally varying temperature $T(y, z, t)$. Figure 18a describes the spatial $(x, y, z)$ coordinate system aligned with the symmetry of a planar microfault of infinte extent parallel to the $x$ direction. Because equation (9) describes a proportionality, the microfault is modelled as propagating in the direction of the shock wave as opposed to the $45^{\circ}$ orientation suggested in Figure 2. $\mathrm{Z}=$ UStf is the distance that the shock wave has propagated into

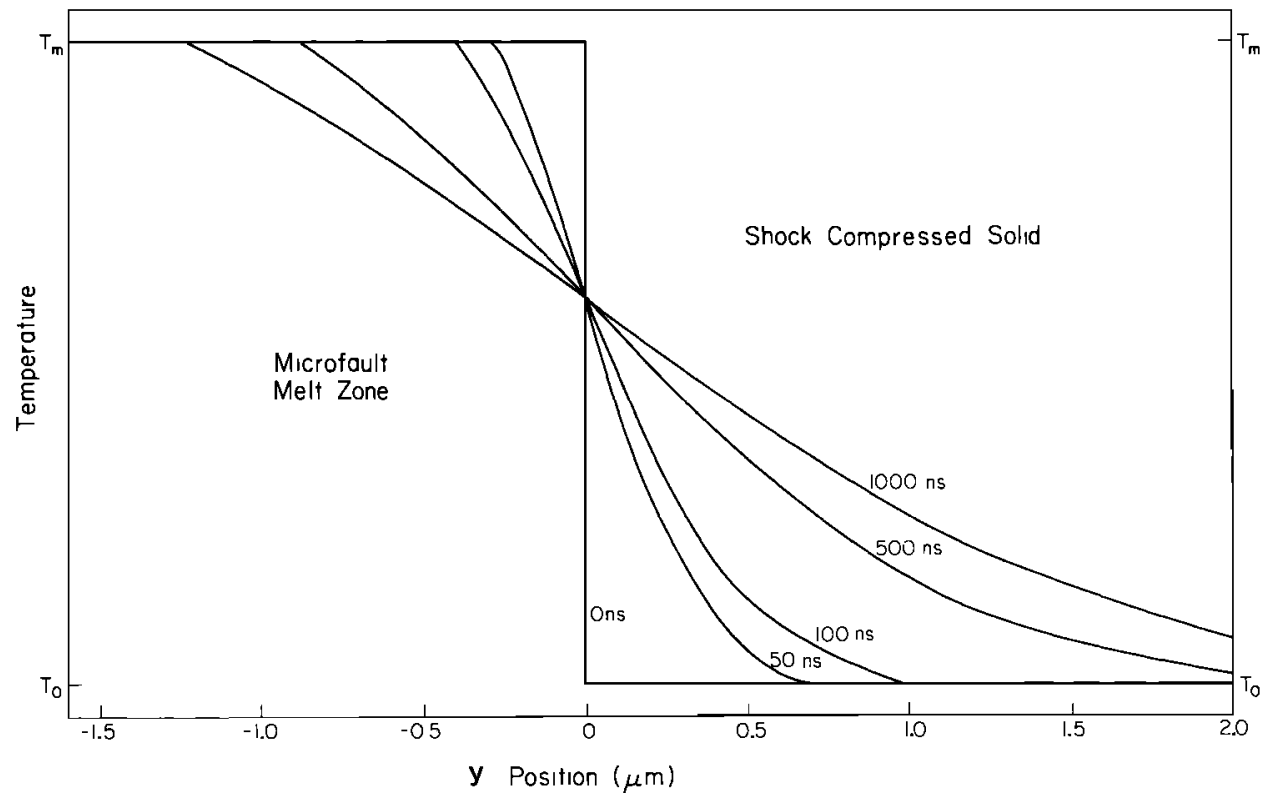

Fig. $16 \mathrm{~b}$. Temperature distribution in the region of the initial microfault boundary at various times. 

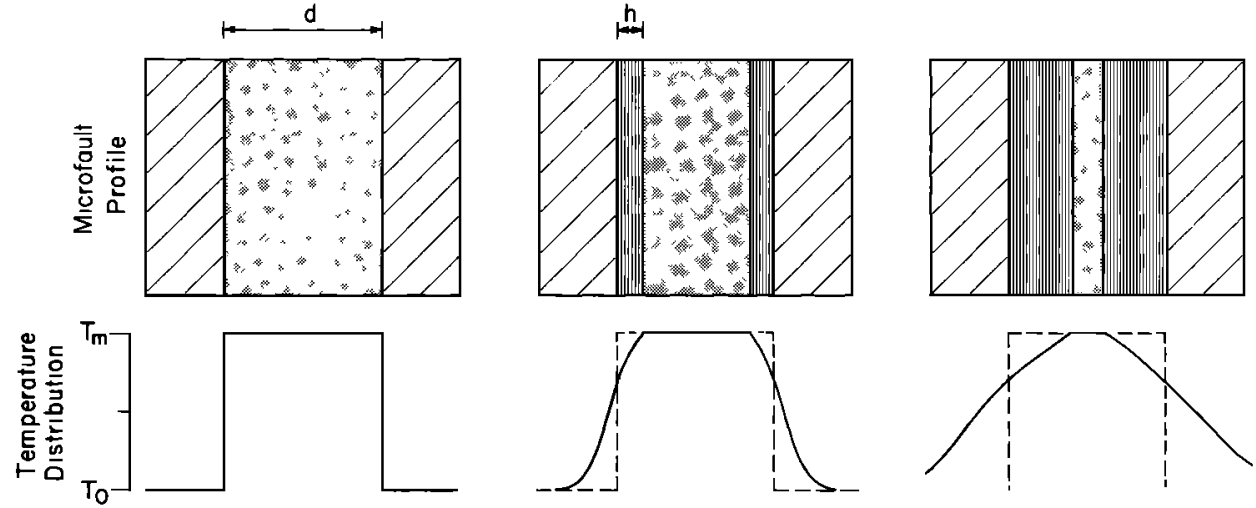

$\dagger=0$

$t=t_{2}$

$t=t_{3}$

Fig. 17. Evolution and cooling history of a microfault for various times. At $t=0$, microfault is a layer of melt (shaded gray) at $T_{m}$ surrounded by solid compressed material (hatched area) at $T_{0}$, while at $t_{2}$ and $t_{3}$, partial and complete crystallization (areas filled with close vertical lines), respectively, is indicated.

the sample at the end of the gate time. Due to the symmetry of the microfault and the rapid propagation of the shock wave relative to the conduction of heat on the time scale of the experiments, only conduction of heat in the y direction normal to the microfault, as described by equations (6), (7), and (8), is recognized.

Equation (9) was evaluated numerically by an algorithm which integrated equation (1) by summing of step functions over small temporal and spatial intervals. In the alogorithm, the two-dimensional region $-\mathrm{b} \leq \mathrm{y} \leq \mathrm{Y}$ and $0 \leq \mathrm{z}<\mathrm{Z}$ is broken up into blocks with dimensions of $\Delta y=10^{-7} \mathrm{~m}$ by $\Delta \mathrm{z}$ $=U_{S} \Delta t$, where $\Delta t=10^{-9}$ s. For each time $t_{0}+n \Delta t$, where $n$ is an integer and $0 \leq \mathrm{n} \leq\left(\mathrm{tf}_{\mathrm{f}}-\mathrm{t}_{\mathrm{o}}\right) / \Delta \mathrm{t}$, a temperature $\mathrm{T}$ for each block was calculated using the assumptions above with the parameters of Table 2; this temperature was then used in equation (1) to find a spectal radiance intensity contribution which was then summed to the total collected spectral energy $\mathrm{E}_{\lambda}$ at a wavelength $\lambda$. A calculated "synthetic" spectra was formed by evaluating equation (9) at 100 equally spaced wavelengths from 400 to $900 \mathrm{~nm}$. Finally, the gray body temperature of this spectra was determined by regression of equation (3) as in analysis of the actual experiments.

Here, the y spatial variables were chosen such that $\mathrm{Y}=$ $10 \mathrm{~b}$ suggestive of an effective emissivity of 0.09 , with values of $b$ ranging from 1 to $10 \mu \mathrm{m}$. Typical experimental gate times of $t_{0}=300 \mathrm{~ns}$ and $t_{f}=600 \mathrm{~ns}$ were applied together with an assumed melting temperature of $\mathrm{T}_{\mathrm{m}}=3000 \quad \mathrm{~K}$ and two separate cases of shocked continuum temperatures of $\mathrm{T}_{\mathrm{o}}=$ $2000 \mathrm{~K}$ and $T_{0}=1000 \mathrm{~K}$. The least squares fit gray body temperatures determined from the resulting calculated spectra are plotted versus initial microfault melt zone thickness $b$ in Figure $18 \mathrm{~b}$. The upper thick line and the lower gray area describes temperatures within $95 \%$ confidence limits determined when the continuum temperature are $\mathrm{T}_{\mathbf{0}}=1000 \mathrm{~K}$ and $\mathrm{T}_{\mathrm{O}}=2000 \mathrm{~K}$, respectively. The least squares fit temperatures are most representative of the melting temperature of the material with greater temperature differences $\Delta \mathrm{T}=\mathrm{T}_{\mathrm{m}}-\mathrm{T}_{\mathrm{O}}$, and larger initial microfault thicknesses. If $\Delta \mathrm{T}=2000 \mathrm{~K}$ as would be suggested by the continuum temperature estimates of Wackerle [1962], the observed temperatures should well represent the melting temperature of the material even for small initial microfault thicknesses $(\approx 1.8 \mu \mathrm{m})$. Alternatively, if the continuum temperature estimates of Kondo and Sawaoka [1981] hold, the observed gray body temperature would underestimate the melting temperatures by at least $200 \mathrm{~K}$. As noted in earlier discussion, we believe the shocked continuum estimates of Wackerle [1962] and Kondo and Sawaoka [1981] to be lower and upper limits, respectively, the actual continuum temperature being somewhere between; and we maintain that the observed group 2 temperatures are representative of the fusion temperature of $\mathrm{SiO}_{2}$ within the stated uncertainties and assuming this relatively simple microfault model holds.

The above modelling of microfault cooling may not be representative of a microfault's history for a number of reasons. Shock recovery observations favor the nucleation of small particles of solid stishovite as depicted in Figure 2b [Ashworth and Schneider, 1985] as opposed to a uniform freezing front advancing into the molten zone of the model. Additionally, the present model does not take into account the kinetics of crystallization and it appears that only small amounts of a silicate can nucleate from the melt on the time scale of a shock experiment [Rigden et al., 1988]. Quartz crystallization from a melt as a function of pressure is not yet well understood; however, recent experimental work on the crystallization of quartz from fused quartz suggests that crystallization rate increases with pressure ap to $4 \mathrm{GPa}$ [Fratello et al., 1980].

Another possible weakness of the above model is the somewhat idealized boxcar temperature distribution for the microfault. The lack of shock damage in the permanently densified bleck of fused silica found surrounded by melt zones in the shock recovery experiments of Anan'in et al. [1974b] mentioned earlier suggest that these solid regions are simply isentropically compressed by the shock wave and are consequently at the continuum temperature $\mathrm{T}_{\mathrm{o}}$ immediately behind the shock front. The assumption that the microfault may be described as a zone of melt at a uniform fusion temperature $\mathrm{T}_{\mathrm{m}}$ may not be as accurate. For example, models of the deposition of energy dissipated by shock compression into uniformly spaced planes can yield localized temperatures as high as $10,000 \mathrm{~K}$ for quartz [Grady, 1980], and these predicted high-temperature excursions could be a large source of error in our analysis and in the interpretation of the observed temperatures in field 2 as fusion temperatures. However, this model ignores both use of some of the deposited energy in the production of melt, with the result that the high temperatures should be bufferred to some extent, and the possible initial deposition of the energy over noninfinitesimal planar volumes through nonbrittle deformation of the material. Finally, we believe that the 
a)

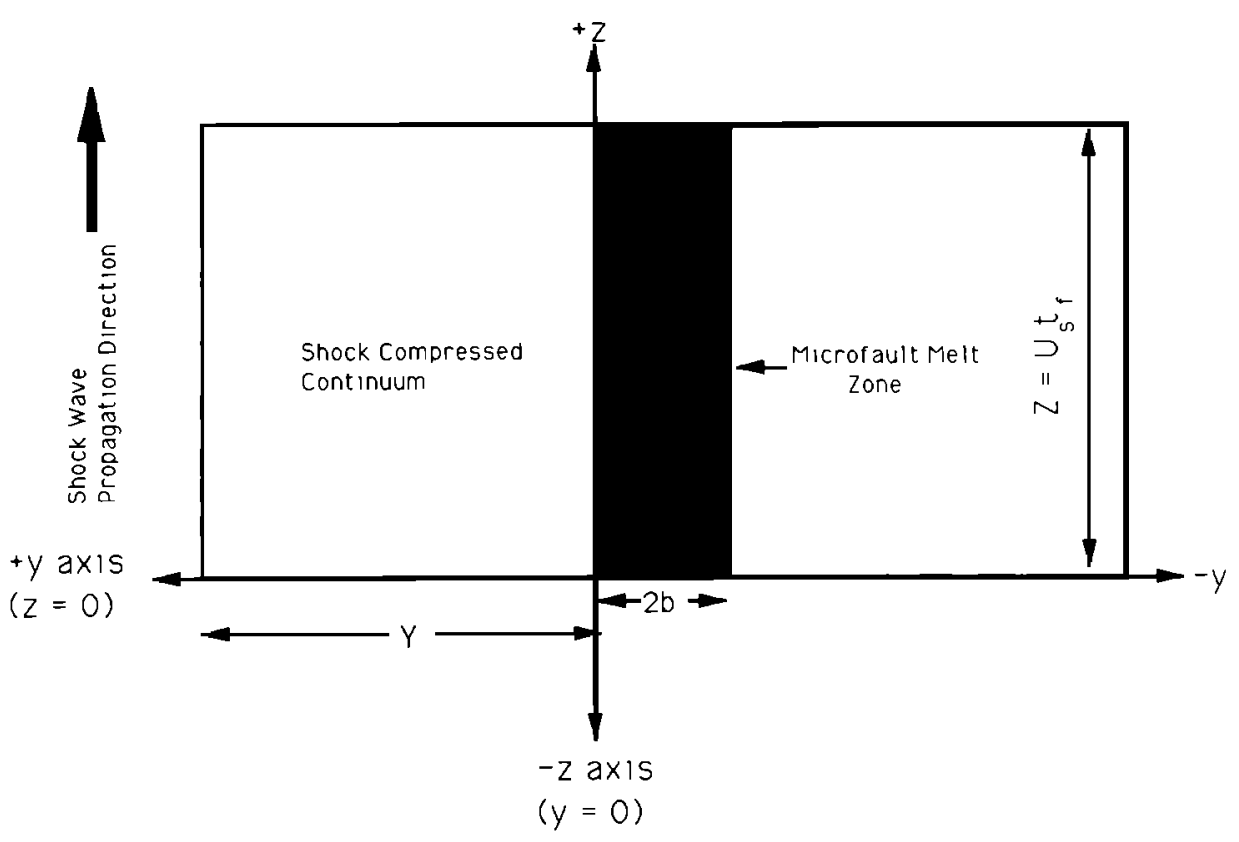

b)

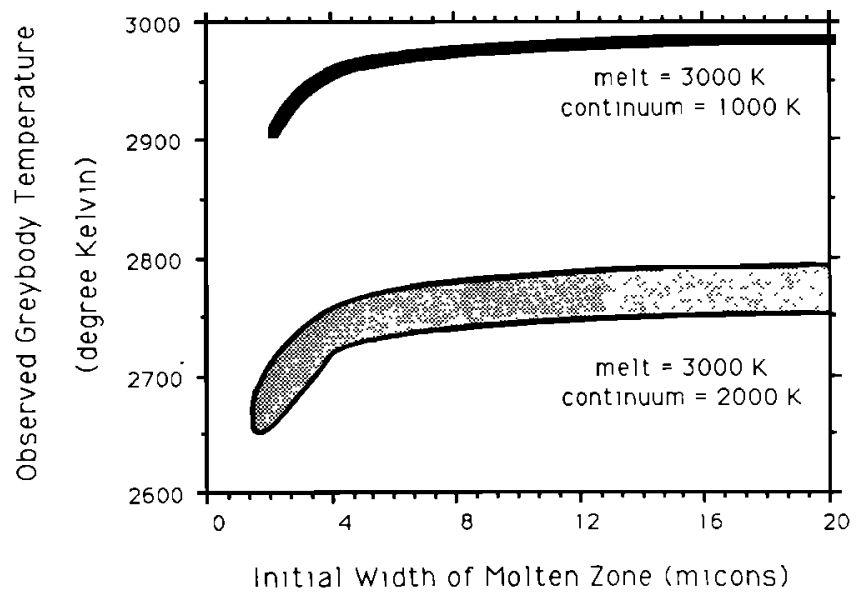

Figure 18 (a) Description of microfault model coordinate system; $x$ axis is normal to page. (b) The $95 \%$ confidence intervals for best fit microfault model gray body temperatures versus initial microfault melt thickness.

essentially constant observed gray body temperatures of field 2 , their low $95 \%$ gray body temperature confidence intervals $(<26 \mathrm{~K})$ from the least squares fits of the spectra, and the apparent agreement of these temperatures with the higherpressure melting data of Lyzenga et al. [1983] (Figure 13b) support interpretation of these temperatures as being representative of the melting temperature of fused silica at high pressure.

\section{Comparison of New Melting Data With Earlier Results}

The proposed estimates (Figure 13a and Table 1) for the melting temperature of silica between 20 and $30 \mathrm{GPa}$ (hatched area of Figure 19) are compared to melting data for $\mathrm{Mg}_{2} \mathrm{SiO}_{4}$ to $15 \mathrm{GPa}$ [Ohtani and Kumazawa, 1981], $\mathrm{MgSiO}_{3}$ to $4.6 \mathrm{GPa}$ [Boyd et al., 1964], $\left(\mathrm{Mg}_{0.9} \mathrm{Fe}_{0.1}\right) \mathrm{SiO}_{3}$ from 18 to $60 \mathrm{GPa}$ [Heinz and Jeanloz, 1987], and $\mathrm{SiO}_{2}$ to
2.5 GPa [Jackson, 1976]. According to Figure 19, both

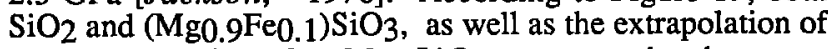
the melting data for $\mathrm{Mg}_{2} \mathrm{SiO}_{4}$, are nearly the same temperature.

Using the melting temperatures of Figure 19 and phase diagrams at the pressures of 1 atm and $2.5 \mathrm{GPa}$ the solidus temperatures in the system $\mathrm{Mg}_{2} \mathrm{SiO}_{4}-\mathrm{SiO}_{2}$ are estimated. The room pressure phase diagram (Figure 20a) after Chen and Presnall [1975] and Bowen and Anderson [1914] displays a peritectic point at a composition of $60.6 \mathrm{wt}$ $\% \mathrm{SiO}_{2}$. With increasing pressure, the composition of $\mathrm{MgSiO}_{3}$ becomes an end-member component with the appearance of a $\mathrm{Mg}_{2} \mathrm{SiO}_{4}-\mathrm{MgSiO}_{3}$ eutectic (Figure 20b) [Chen and Presnall, 1975]. Based on studies of two phase systems [Kennedy and Higgins, 1972; Newton et al., 1962], the depth of the eutectic trough is expected to increase with increasing pressure; that is, the minimum difference between the melting temperatures of a pure end-member 


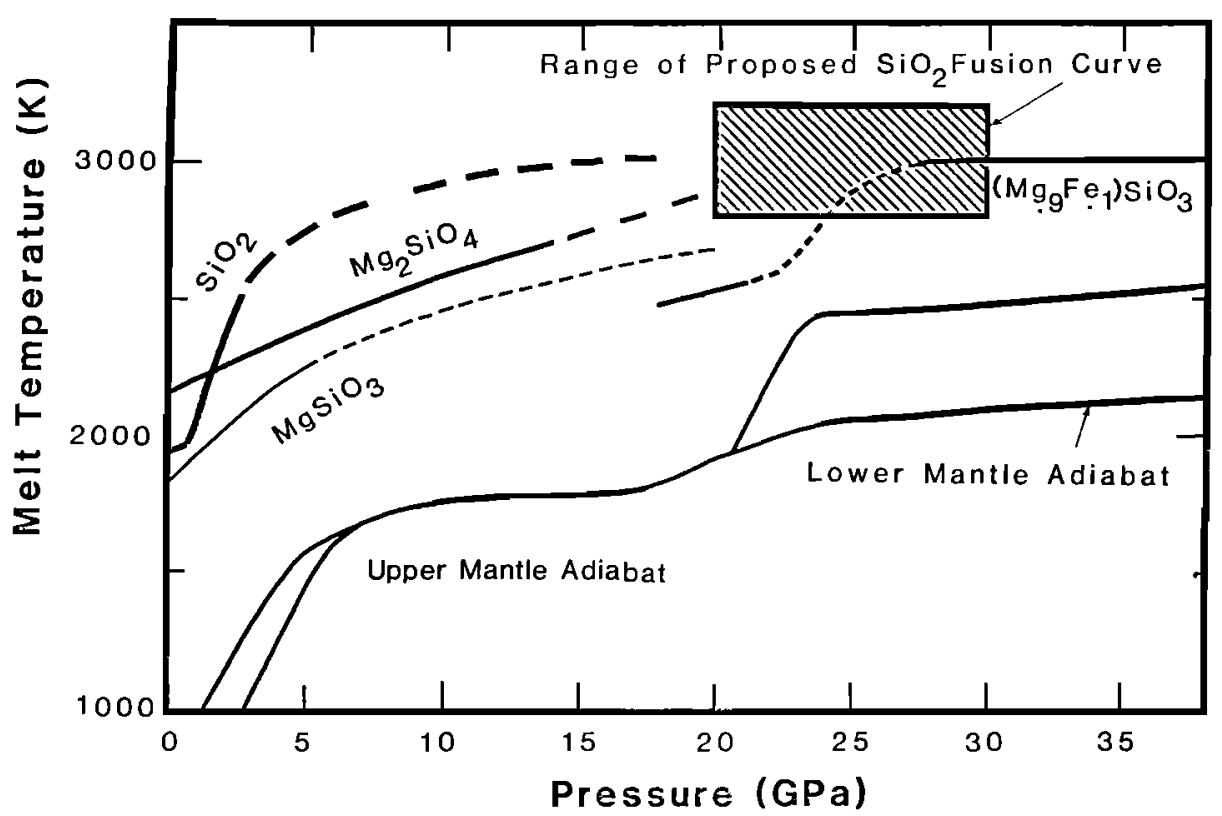

Fig. 19. Comparison of proposed $\mathrm{SiO}_{2}$ fusion curve (hatched region) with measured and inferred melting data for $\mathrm{SiO}_{2}$ to $2.5 \mathrm{GPa}$ [Jackson, 1976], $\mathrm{MgSiO} 3$ to $5.0 \mathrm{GPa}$ [Boyd et al., 1964], $\mathrm{Mg}_{2} \mathrm{SiO}_{4}$ to $15 \mathrm{GPa}$ [Ohtani and Kumazawa, 1981], and (Mg0.9Fe0.1)SiO3 from 18 to $38 \mathrm{GPa}$ [Heinz and Jeanloz, 1987 ]. Inferred lower mantle adiabats from Jeanloz and Richter [1979] and upper mantle adiabats from Turcotte and Schubert [1982].

component and the eutectic composition is observed at low pressure. In the extrapolations to higher pressures, the depth of the eutectic troughs are assumed to be the same as in Figure 20b; thus the eutectic temperatures at higher pressures represent a maximum value. Additionally, it is assumed in the extrapolations that the composition of the two eutectics of Figure $20 \mathrm{~b}$ is constant; this assumption appears to be valid for the $\mathrm{MgSiO}_{3}-\mathrm{SiO}_{2}$ eutectic [Chen and Presnall, 1975] but may be in error by $\sim 3 \%$ for the other eutectic as the hydrous $\mathrm{Mg}_{2} \mathrm{SiO}_{4}-\mathrm{MgSiO}_{3}$ system has a eutectic composition near 53 wt $\% \mathrm{SiO}_{2}$ [Kato and Kumazawa, 1986]. Using the depth of the eutectic well from the $\mathrm{MgSiO}_{3}$ melting temperature as determined by Chen and Presnall [1975] at 2.5 GPa (Figure 20b) and extrapolating to higher pressures with the melting temperatures of Figure 19 , we infer that the maximum solidus temperatures in the $\mathrm{Mg}_{2} \mathrm{SiO}_{4}-\mathrm{SiO}_{2}$ system would be $\sim 2500 \mathrm{~K}$ at $12.5 \mathrm{GPa}$ (Figure $20 \mathrm{c}$ )and $2650 \mathrm{~K}$ at 20.0 $\mathrm{GPa}$ (Figure 20d).

Inclusion of the component $\mathrm{FeO}$ would further depress the solidus temperatures; for an estimated mantle $\mathrm{Fe} /(\mathrm{Fe}+$ $\mathrm{Mg}$ ) ratio of $10 \%$ [Jeanloz and Thompson, 1983], the solidus temperature may be further depressed by $\sim 130 \mathrm{~K}$ as estimated from the drop in the solidus temperature in the system $\mathrm{Mg}_{2} \mathrm{SiO}_{4}-\mathrm{Fe}_{2} \mathrm{SiO}_{4}$ at 1 atm [Bowen and Schairer, 1935]. The maximum solidus temperatures within the mantle may thus be $\sim 2370 \mathrm{~K}$ at $12.5 \mathrm{GPa}$ and $2520 \mathrm{~K}$ at $20.0 \mathrm{GPa}$.

Weertman [1970] suggests that the effective viscosity of a solid at a constant creep rate is given by

$$
\eta=\operatorname{Cexp}\left(g \frac{T_{m}}{T}\right)
$$

where $\eta$ is the effective viscosity, $C$ is a constant, $T_{m}$ is the melting temperature, $T$ is the temperature of the material, and $\mathrm{g}$ is a dimensionless constant empirically found to be $\sim 18.0$ for most metals. The applicability of equation (10) to brittle minerals is unknown; recent work on polycrystalline olivine [Green and Borch, 1987], however, indicates that at constant homolgous temperature $T / T_{m}$ the flow stress is independent of pressure to $2.5 \mathrm{GPa}$. The ratio of the proposed melting curve of $\mathrm{SiO}_{2}\left(\mathrm{~T}_{\mathrm{m}}\right)$ to an upper mantle geotherm (T) [Turcotte and Schubert, 1982] at pressures between 6.5 and $20 \mathrm{GPa}$ is nearly constant near 0.6 , suggesting little variation in the effective viscosity from 200 to $600 \mathrm{~km}$ within the Earth in agreement with the inferences of Heinz and Jeanloz [1987].

\section{Conclusion}

The major findings of this study are the following:

1. Fused quartz, like other brittle minerals subject to shock compression, undergoes heterogeneous shock deformation characterized by localized zones of melting between 16 and $30 \mathrm{GPa}$. Evidence for this is supplied by the framing camera photographs that show hot regions which persist and grow during shock compression and the high temperature/low emittance gray body spectra observed between 16 and $30 \mathrm{GPa}$.

2. The observed temperatures reflect the temperature of the localized zones of deformation. Shock recovery and release wave studies suggest that these zones are molten during shock compression. Shock recovery work and the Hugoniot of fused quartz suggest that the high-pressure solid phase (stishovite) is produced within these shear bands or microfaults.

3. The melt temperature within these microfaults may be buffered by the production of the high pressure phase and as such may reflect the liquidus temperature of stishovite at high pressure. This suggests that this temperature is approximately $3000 \mathrm{~K}$ in the pressure range of $20-30 \mathrm{GPa}$ and is independent of pressure.

4. Shock compression becomes more homogeneous with increasing pressure as evidenced by the general increase in emittance with pressure.

5. Shock temperatures observed in the pressure range of 10-16 GPa are up to $2000 \mathrm{~K}$ higher than temperatures at increased shock pressure and appear to be related to the onset of the fused quartz-stishovite phase transformation. 

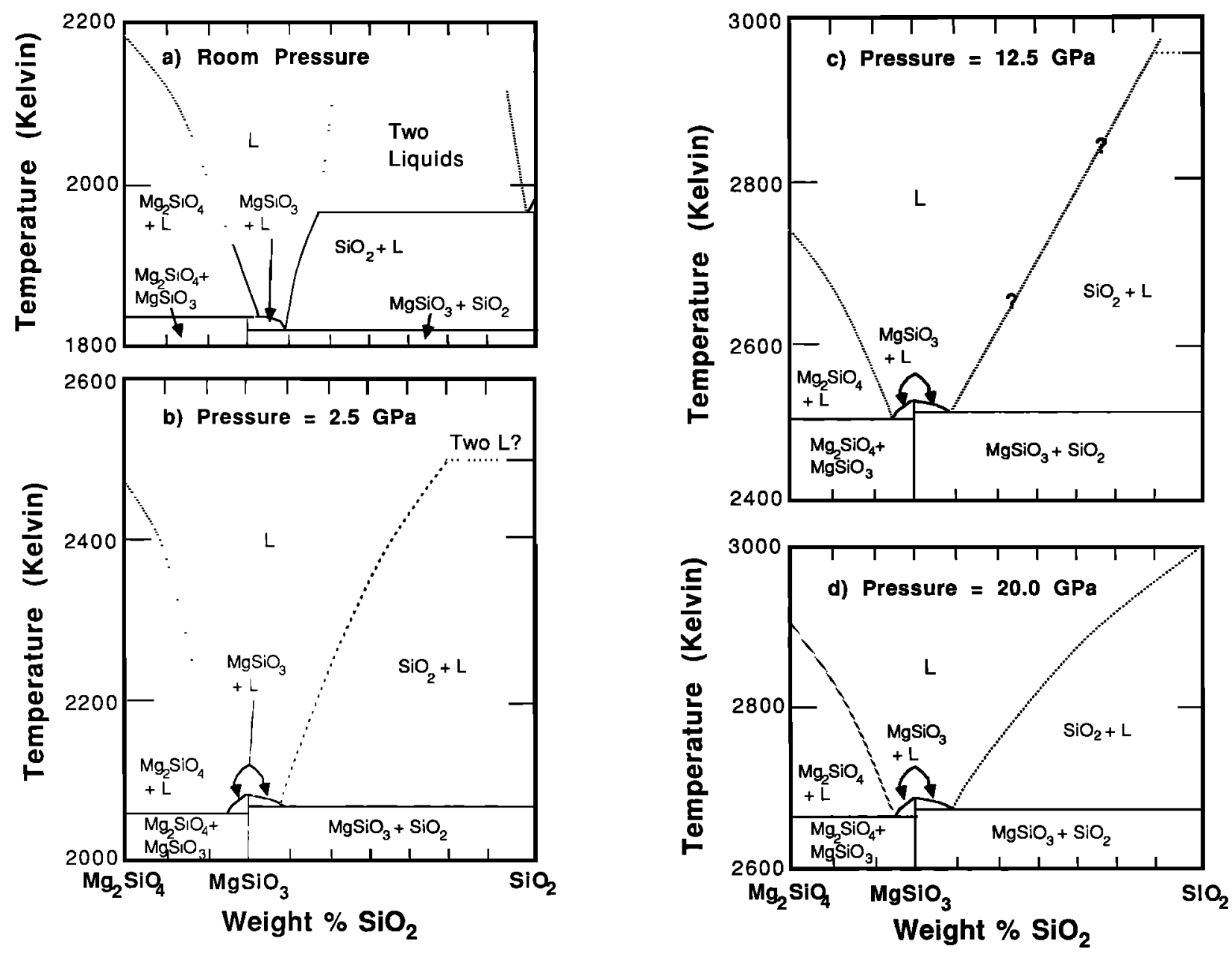

Fig. 20. (a) Measured $\mathrm{Mg}_{2} \mathrm{SiO}_{4}-\mathrm{SiO}_{2}$ phase diagram at $1 \mathrm{~atm}$ after Chen and Presnall [1975]. $\mathrm{L}$ represents melt region. (b) $\mathrm{Mg}_{2} \mathrm{SiO}_{4}-\mathrm{SiO}_{2}$ phase diagram at $2.5 \mathrm{GPa}$. (c) Proposed $\mathrm{Mg}_{2} \mathrm{SiO}_{4}-\mathrm{SiO}_{2}$ phase diagram at $12.5 \mathrm{GPa}$. Depth of eutectics as measured from $\mathrm{MgSiO}_{3}$ melting temperature are the same as in Figure $20 \mathrm{~b}$. (d) Proposed $\mathrm{Mg}_{2} \mathrm{SiO}_{4}-\mathrm{SiO}_{2}$ phase diagram at $20 \mathrm{GPa}$. Depth of eutectics as measured from $\mathrm{MgSiO}_{3}$ melting temperature are the same as in Figure $20 \mathrm{~b}$.

These high temperatures and subsequent decrease in temperature with increasing pressure are not understood. Similar behavior is seen in $\mathrm{NaCl}$ over the $\mathrm{B} 1-\mathrm{B} 2$ phase transition region [Schmitt et al., 1988].

6. Solidus temperatures for $\mathrm{Mg}_{2} \mathrm{SiO}_{4}-\mathrm{SiO}_{2}$ system inferred from the present proposed melting curve for $\mathrm{SiO}_{2}$ at high pressure together with other melting data suggest that the maximum solidus temperatures within the mantle are close to $2370 \mathrm{~K}$ at $12.5 \mathrm{GPa}$ and $2520 \mathrm{~K}$ at $20.0 \mathrm{GPa}$. Comparison of the proposed $\mathrm{SiO}_{2}$ melting curve with reasonable predicted geotherm temperatures suggests that the effective viscosity between 200 and $600 \mathrm{~km}$ within the mantle is nearly constant.

Acknowledgements. The authors wish to thank Epapradito Gelle, Michael Long, William Barber, and Wayne Miller for technical assistance. Discussions and aid from Gregory Miller, Philip Ihinger, William Anderson, Bob Svendsen, Michael Caroll, Peter Wyllie, and Brian Quinn were appreciated. This work supported under NSF grant EAR-86-08249 and NASA contract NGL-05-002-105. D. Schmitt gratefully acknowledges the support of the Sir James Lougheed Graduate Fellowship, Alberta Heritage Scholarship Fund, from 1984 to 1986 . Contribution 4535, California Institute of Technology, Pasadena, California.

\section{References}

Ahrens, T.J., and J.T. Rosenberg, Shock metamorphism experiments on quartz and plagioclase, in Shock Metamorphism in Natural Materials, edited by B.M. French and N.M. Short, pp. 59-81, Mono Press, Baltimore, Md., 1968.

Ahrens, T.J., D.L. Anderson, and A.E. Ringwood, Equations of state and crystal structures of highpressure phases of shocked silicates and oxides, Rev. Geophys., 7, 667-707, 1969.

Al'tshuler, L.V., R.F. Trunin, and G.V. Simakov, Shock wave compression of periclase and quartz and the composition of the Earth's lower mantle, Izv. Acad. Sci. USSR Phys. Solid Earth, Engl. Transl., 10, 657$660,1965$.

Anan'in, A.V., O.N. Breusov, A.N. Dremin, S.V. Pershin, and V.F. Tatsii, The effect of shock waves on silicon dioxide, I, Quartz, Combust. Explos. Shock Waves, Engl. Transl., 10, 372-379, 1974a.

Anan'in, A.V., O.N. Breusov, A.N. Dremin, S.V. Pershin, A.I. Rogacheva, and V.F. Tatsii, Action of shock waves of silicon dioxide, II, quartz glass, Combust. Explos. Shock Waves, Engl. Transl., 10, 504-508, $1974 \mathrm{~b}$.

Arndt, J., and D. Stöffler, Anomalous changes in some 
properties of silica glass densified at very high pressures, Phys.Chem.Glasses, 10, 117-124, 1969.

Arndt, J., U. Hornemann, and W.F. Muller, Shockwave densification of silica glass, Phys.Chem.Glasses, 12 , 1-7, 1971.

Ashworth, J.R., and H. Schneider, Deformation and transformation in experimentally shock-loaded quartz, Phys. Chem. Miner., 11, 241-249, 1985.

Barker, L.M., and R.E. Hollenbach, Shock-wave studies of PMMA, fused silica, and sapphire, J. Appl. Phys., 41, 4208-4226, 1970.

Boslough, M.B., A model for time dependence in shockinduced thermal radiation of light, J. Appl. Phys., 58, 3394-3399, 1985.

Boslough, M.B., T.J. Ahrens, and A.C. Mitchell, Shock temperatures in anorthite glass, Geophys.J. $\underline{R}$, astron. Soc., 84, 475-489, 1986.

Bowen, N.L., and O. Anderson, The binary system MgO$\mathrm{SiO}_{2}$, Am. J. Sci., 37, 487-500, 1914.

Bowen, N.L., and J.F. Schairer, The system MgO-FeO$\mathrm{SiO}_{2}$, Am. J. Sci., 29, 151-217, 1935.

Boyd, F.R., J.L. England, and B.T.C. Davies, Effect of pressure on the melting and polymorphism of enstatite, $\mathrm{MgSiO}_{3}$, J. Geophys. Res., 69, 2101-2109, 1964.

Brannon, P.J., C. Konrad, R.W. Morris, E.D. Jones, and J.R. Asay, Studies of the spectral an spatial characteristics of shock-induced luminescence from $X$ cut quartz, J. Appl. Phys., 54, 6374-6381, 1983a.

Brannon, P.J, C.H. Konrad, R.W. Morris, E.D. Jones, and J.R. Asay, Spectral and spatial studies of shock-induced luminescence from quartz, $\underline{\text { Sandia }}$ Report SAND82-2469, p. 84, Sandia Nat. Lab., Albuquerque, N. M., 1983b.

Bridgman, P.W., and I. Simon, Effects of very high pressure on glass, J. Appl. Phys., 24, 405-413, 1953.

Brooks, W.P., Shock-induced luminescence in quartz, J. Appl. Phys., 36, 2788-2790, 1965.

Chao, E.C.T., E.M. Shoemaker, and B.M. Madsen, First natural occurrence of coesite, Science, 132, 220-222, 1960.

Chao, E.C.T., J.J. Fahey, J. Littler, and D.J. Milton, Stishovite, $\mathrm{SiO}_{2}$, a very high pressure new mineral from Meteor Crater, Arizona, J. Geophys. Res., 67, 419-421, 1962

Chen, C., and D.C. Presnall, The system $\mathrm{Mg}_{2} \mathrm{SiO}_{4}-\mathrm{SiO}_{2}$ at pressures up to 25 kilobars, Am. Mineral., $\underline{60}$, 398$406,1975$.

Chhabildas, L.C., and D.E. Grady, Dynamic material response of quartz at high strain rates, Mater. Res. Soc. Symp. Proc., 22, 147-150, 1984.

Chhabildas, L.C. and D.E. Grady, Shock loading behavior of fused quartz, Shock Waves in Condensed Matter-1983, edited by J.R. Asay, R.A. Graham, and G.K. Straub, pp. 175-178, Elsevier Science Publishers, New York, 1984.

Chhabildas, L.C., and J.M. Miller, Release-adiabat measurements in quartz, Sandia Rep. SAND85-1092, p. 25, Sandia Nat. Lab., Albuquerque, N.M., 1985.

Coes, L., A new dense crystalline silica, Science, 118 , $131-132,1953$

Cohen, H.M., and R. Roy, Effects of ultrahigh pressure on glass, J. Am. Ceram. Soc., 44, 523-524, 1961.

Dachille, J., R.J. Zeto, and R. Roy, Coesite and stishovite: stepwise reversal transformation, Science, 131, 1675-1676, 1963.

Davies, G.F., Equations of state and phase equilibria of stishovite and a coesitelike phase from shock-wave and other data, J. Geophys. Res., 77, 4920-4933, 1972.

Davison, L., and R.A. Graham, Shock compression of solids, Phys. Rep., 55, 255-379, 1979.
DeCarli, P.S., and D.J. Milton, Stishovite: Synthesis by shock wave, Science, 147, 144-145, 1965.

Duvall, G.E., and R. Fowles, Shock waves, in High Pressure Physics and Chemistry, vol. 2, pp. 209-291, edited by R.S. Bradley, Academic, San Diego, Calif., 1963.

Fowles, R., Dynamic compression of quartz, J. Geophys. Res., 72, 5729-5742, 1967.

Fratello, V.J., J.F. Hays, and D. Turnbull, Dependence of growth rate of quartz in fused silica on pressure and impurity content, J. Appl. Phys., 51, 4718-4728, 1980.

Gibbons, R.V., and T.J. Ahrens, Shock metamorphism of silicate glasses, J. Geophys. Res., 76, 5489-5498, 1971.

Grady, D.E., Processes occurring in shock wave compression of rocks and minerals, in High Pressure Research, Applications in Geophysics, edited by M.H. Manghnani, and S. Akimoto, pp. 389-438, Academic, San Diego, Calif., 1977.

Grady, D.E., Shock deformation of brittle solids, J. Geophys. Res. 85, 913-924, 1980.

Grady, D.E., W.J. Murri, and G.R. Fowles, Quartz to stishovite: wave propagation in the mixed phase region, J. Geophys. Res., 79, 332-338, 1974.

Grady, D.E., W.J. Murri, and P.S. DeCarli, Hugoniot sound velocities and phase transformations in two silicates, J. Geophys. Res.. 80, 4857-4861, 1975.

Graham, R.A., Shock-wave compression of X-cut quartz as determined by electrical response

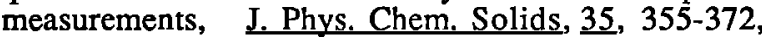
1974.

Gratz, A., Deformation in laboratory-shocked quartz, J. Non Cryst. Solids, 67, 543-558, 1984.

Green, H.W., II, and R.S. Borch, The pressure dependence of creep, Acta Metall., 35, 1301-1305, 1987.

Grimsditch, M., Polymorphism in amorphous $\mathrm{SiO}_{2}$, Phys. Rev. Lett., 52, 2379-2381, 1984.

Grover, R., and P.A. Urtiew, Thermal relaxation at interfaces following shock compression, J. Appl. Phys., 45, 146$152,1974$.

Hayes, D.B., and R.A. Graham, Yielding of shock-loaded X-cut quartz, Bull. Amer. Phys. Soc., 23, 71, 1978.

Heinz, D.L., and R. Jeanloz, Measurement of the melting curve of $\left(\mathrm{Mg}_{0.9} \mathrm{Fe}_{0.1}\right) \mathrm{SiO}_{3}$ at lower mantle conditions and its geophysical implications, J. Geophys. Res., 92, 11,437-11,444, 1987.

Hemley, R.J., H.K. Mao, P.M. Bell, and B.O. Mysen, Raman spectroscopy of $\mathrm{SiO}_{2}$ glass at high pressure, Phys. Rev. Lett., 57, 747-750, 1986.

Holm, J.L., O.J. Kleppa, and E.F. Westrum, Thermodynamics of polymorphic transformationin silica. Thermal properties from 5 to $1070 \mathrm{~K}$ and pressuretemperature stability fields for coesite and stishovite, Geochim. Cosmochim. Acta, 31, 2289-2307, 1967.

Jackson, I., Melting of the silica isotypes $\mathrm{SiO}_{2}, \mathrm{BeF}_{2}$ and $\mathrm{GeO}_{2}$ at elevated pressures, Phys. Earth. Planet. Inter., 13, 218-231, 1976.

Jackson, I., and T.J. Ahrens, Shock wave compression of single-crystal forsterite, J. Geophys. Res., $\underline{84}, 3039$ 3048, 1979.

Jeanloz, R., and F.M. Richter, Convection, composition and the thermal state of the lower mantle, J. Geophys. Res., 84, 5497-5504, 1979.

Jeanloz, R., and A.B. Thompson, Phase transitions and mantle discontinuities, Rev. Geophys, 21, 51-74, 1983.

Jones, O.E., and R.A. Graham, Shear strength effects on phase transition pressures determined from shockcompression experiments, Accurate Characterization of the High Pressure Environment, edited by E.C. Lloyd, N. B. S. Spec. Publ., 326, 229-237, 1971.

Kato, T., and M. Kumazawa, Melting and phase relations 
in the system $\mathrm{Mg}_{2} \mathrm{SiO}_{4}-\mathrm{MgSiO}_{3}$ at $20 \mathrm{GPa}$ under hydrous conditions, J. Geophys. Res., 21, 9351-9355, 1986.

Kennedy, G.C., and G.H. Higgins, Melting temperatures in the Earth's mantle, Tectonophysics, 13, 221-232, 1972.

Kieffer, S.W., Shock metamorphism of the coconino sandstone at Meteor Crater, Arizona, J. Geophys. Res, 76, 5449-5473, 1971.

Kleeman, J.D., and T.J. Ahrens, Shock-induced transition of quartz to stishovite, J. Geophys. Res., 78, 5954$5960,1973$.

Kondo, K., and T.J. Ahrens, Heterogeneous shock-induced thermal radiation in minerals, Phys. Chem. Minerals, $\underline{9}$, 173-181, 1983a.

Kondo, K., and T.J. Ahrens, Shock-induced spectra of fused quartz, J. Appl. Phys. 54, 4382-4385, $1983 \mathrm{~b}$.

Kondo, K., and A. Sawaoka, Electrical measurements on fused quartz under shock compression, J. Appl. Phys., 52, 5084-5089, 1981.

Kondo, K., I. Satoshi, and A. Sawaoka, Nonlinear pressure dependence of the elastic moduli of fused quartz up to $3 \mathrm{GPa}, \underline{\mathrm{J}}$. Appl. Phys., 52, 2826-2831, 1981 .

Kuskov, O.L., and O.B. Fabrichnaya, The $\mathrm{SiO}_{2}$ polymorphs: The equations of state and thermodynamic properties of phase transformations, Phys. Chem. Minerals, 14, 58-66, 1987.

Lyzenga, G.A., and T.J. Ahrens, Shock temperature measurements in $\mathrm{Mg}_{2} \mathrm{SiO}_{4}$ and $\mathrm{SiO}_{2}$ at high pressures, Geophys. Res. Lett., 7, 141-144, 1980.

Lyzenga, G.A., and T.J. Ahrens, Shock temperatures of $\mathrm{SiO}_{2}$ and their geophysical implications, J. Geophys. Kes., 88, 2431-2444, 1983.

Lyzenga, G.A., T.J. Ahrens, and A.C. Mitchell, Temperatures induced by shock waves in minerals: Applications to geophysics, High Pressure Research in Geophysics, edited by S. Akimoto and M.H. Manghnani,Adv. Earth Planet.Sci., 12, 579-594, 1983.

MacKenzie, J.D., High pressure effects on oxide glasses, I, Densification in the rigid state, J. Am. Ceram. Soc, 46, 461-470, 1963.

Marsh, S.P., LASL Shock Hugoniot Data, pp. 658, University of California Press, Berkeley, 1980.

Mashimo, T., K. Nishii, T. Soma, and A. Sawaoka, Some physical properites of amorphous $\mathrm{SiO}_{2}$ synthesized by shock compression of alpha quartz, Phys. Chem. Minerals, 5, 367-377, 1980.

McQueen, R.G., J.N. Fritz, and S.P. Marsh, On the equation of state of stishovite, J.Geophys. Res., 68, 2319-2322, 1963.

Meade, C., and R. Jeanloz, Frequency dependent equation of state of fused silica to $10 \mathrm{GPa}$, Phys. Rev. B., 35, 236244, 1987.

Newton, R.C., A. Jayaraman, and G.C. Kennedy, The fusion curves of the alkali metals up to 50 kilobars, J. Geophys. Res., 67, 2559-2566, 1962.

Ohtani, E., and M. Kumazawa, Melting of forsterite $\mathrm{Mg}_{2} \mathrm{SiO}_{4}$ up to $15 \mathrm{GPa}$, Phys. Earth Planet. Inter., 27, 32-38, 1981.

Podurets, M.A., G.V. Simakov, and R.F. Trunin, On the phase equilibrium in shock-compressed quartz and the kinetics of phase transitions, Izv. Acad. Sci. USSR Phys. Solid Earth, Engl. Trans., 12, 419-424, 1976.

Rigden, S.M., T.J. Ahrens, and E.M. Stolper, Shock compression of molten silicate: Results for a model basaltic composition, J. Geophys. Res., 93, 367$382,1987$.

Schaal, R.B., and F. Horz, Shocked rutilated quartz (abstract), Eos Trans. AGU, 58, 1180, 1977.
Schmitt, D.R., and T.J. Ahrens, Temperatures of shockinduced shear instabilities and their relationship to fusion curves, Geophys. Res. Lett., 10, 1077-1080, 1983.

Schmitt, D.R., B. Svendsen, and T.J. Ahrens, Shock induced radiation from minerals, in Shock Waves in Condensed Matter, edited by Y.M. Gupta, pp. 261-265, Plenum, New York, 1986.

Schmitt, D.R., T.J. Ahrens, and B. Svendsen, Shock induced melting and shear banding in single crystal $\mathrm{NaCl}$, J. Appl. Phys., 63, 99-106, 1988.

Stacey, F.D., Physics of the Earth, pp. 327, John Wiley, New York, 1977.

Stishov, S.M., and S.V. Popova, New dense polymorphic modification of silica, Geokhimiya, 10 , 837-839, 1961.

Stöffler, D., Coesite and stishovite in shocked crystalline rocks, J. Geophys. Res., 76, 5474-5488, 1971.

Stöffler, D., Deformation and transformation of rockforming minerals by natural and experimental shock processes, I, Behavior of minerals under shock compression, Fortschr. Mineral., 49, 50-113, 1972.

Stöffler, D., Deformation and transformation of rock-forming minerals by natural and experimental shock processes, II, Physical properties of shocked minerals, Fortschr. Mineral, 51, 256-289, 1974.

Stolper, E.M., and T.J. Ahrens, On the nature of pressure induced coordination changes in silicate melts and glasses, Geoph. Res. Lett., 14, 1231-1233, 1987.

Sugiura, H., K. Kondo, and A. Sawaoka, Dynamic response of fused quartz in the permanent densification region, J. Appl. Phys., 52, 3375-3382, 1981.

Sugiura, H., K. Kondo, and A. Sawaoka, Shock temperatures in fused silica measured by optical technique, J. Appl. Phys., 53, 4512-4514, 1982.

Svendsen, B., J.D. Bass, and T.J. Ahrens, Optical radiation from shock compressed interfaces, paper presented at U.S.-Japan Research Seminar on High-Pressure Research, U.S. Nat. Sci. Found. and Japan Soc. for the Promotion of Sci., Kahuku, Hawaii, Jan. 13-17, 1986.

Trunin, R.F., G.V. Simakov, M.A. Podurets, B.N. Moiseyev, and L.V. Popov, Dynamic compressibilty of quartz and quartzite at high pressure, Izv. Acad. Sci. USSR Phys. Solid Earth, Engl. Transl. 1, 8-12, 1971.

Turcotte, D.L. and S. Schubert, Geodynamics. Applications of Continuum Physics to Geological Problems, pp. 450, John Wiley, New York, 1982.

Urtiew, P.A., and R. Grover, Temperature deposition caused by shock interactions with material interfaces, J. Appl. Phys., 45, 140-145, 1974.

Wackerle, J., Shock-wave compression of quartz, J. Appl. Phys., 33, 922-937, 1962.

Weast, R.C., CRC Handbook of Chemistry and Physics, CRC Press, Boca Raton, Fla., 1982.

Weertman, J., The creep strength of the Earth's mantle, Rev. Geophys. Space Phys., ㅁ, 145-168, 1970.

T. J. Ahrens, Seismological Laboratory, California Institute of Technology, Pasadena, CA 91125.

D. R. Schmitt, Institute for Earth and Planetary Physics and Department of Physics, 412 Avadh Bhatia Physics Laboratory, University of Alberta, Edmonton, Alberta, Canada T6G 2J1.

(Received November 17, 1987; revised December 6, 1988; accepted December $16,1988$. ) 